Florida International University FIU Digital Commons

$11-15-2004$

\title{
Causal attributions for success or failure by passing and failing students in college algebra
}

Georgina Cortés Suárez

Florida International University

DOI: $10.25148 /$ etd.FI14061526

Follow this and additional works at: https://digitalcommons.fiu.edu/etd

Part of the Higher Education Commons

\section{Recommended Citation}

Cortés Suárez, Georgina, "Causal attributions for success or failure by passing and failing students in college algebra" (2004). FIU Electronic Theses and Dissertations. 2660.

https://digitalcommons.fiu.edu/etd/2660 
Miami, Florida

A dissertation submitted in partial fulfillment of the

requirements for the degree of

DOCTOR OF EDUCATION

in

HIGHER EDUCATION

by

Georgina Cortés-Suárez

2004 
To: Dean Linda Blanton

College of Education

This dissertation, written by Georgina Cortés-Suárez, and entitled Causal Attributions for Success or Failure by Passing and Failing Students in College Algebra, having been approved in respect to style and intellectual content, is referred to you for judgment.

We have read this dissertation and recommend that it be approved.

Carlos M. Alvarez

Oreg K. Dubrow

Barry Greenberg

Janice R. Sandiford, Major Professor

Date of Defense: November 15, 2004

The dissertation of Georgina Cortés-Suárez is approved.

Dean Linda Blanton

College of Education

Dean Douglas Wartzok

University Graduate School

Florida International University, 2004 
(C) Copyright 2004 by Georgina Cortés-Suárez

All rights reserved. 


\section{DEDICATION}

To my husband, George and my son, Andrew who selflessly supported and inspired me during the process of writing this dissertation. 


\section{ACKNOWLEDGMENTS}

This was a long and powerful journey and many contributed to it. I would like to first extend my appreciation to the members of my dissertation committee: Dr. Janice Sandiford, Major Professor, Dr. Carlos Alvarez, Dr. Greg Dubrow, and Dr. Barry Greenberg for their valuable and insightful guidance. To Dr. Sandiford I owe a special thank you for her support and encouragement over the past seven years.

My deepest gratitude to my colleagues at Miami Dade College for putting up with my moments of dissertation panic. I especially want to thank Roberto J. Hernandez, Dr. Rolando Montoya, and Dr. Lois Willoughby who have been the source of my inspiration during this process. We began our relationship as Miami Dade College and doctoral studies colleagues and we are now lifelong friends. I thank them for their integrity, encouragement, generosity, and patience. Special thanks also go to Dr. Rene Garcia for his valuable help. To Dr. Joanne Bashford, Dr. Cathy Morris and the staff at Miami Dade College's Office of Institutional Research I extend my sincere appreciation as well. My gratitude to the mathematics faculty and students who participated in this study for contributing their valuable class time.

Finally, I want to acknowledge and give special thanks to my husband George for his support, encouragement, extraordinary patience, editing, and most of all his love. 


\title{
ABSTRACT OF THE DISSERTATION
}

\section{CAUSAL ATTRIBUTIONS FOR SUCCESS OR FAILURE BY PASSING AND}

\section{FAILING STUDENTS IN COLLEGE ALGEBRA}

\author{
by
}

\author{
Georgina Cortés-Suárez
}

Florida International University, 2004

Miami, Florida

Professor Janice R. Sandiford, Major Professor

Success in mathematics has been identified as a predictor of baccalaureate degree completion. Within the coursework of college mathematics, College Algebra has been identified as a high-risk course due to its low success rates.

Research in the field of attribution theory and academic achievement suggests a relationship between a student's attributional style and achievement. Theorists and researchers contend that attributions influence individual reactions to success and failure. They also report that individuals use attributions to explain and justify their performance. Studies in mathematics education identify attribution theory as the theoretical orientation most suited to explain academic performance in mathematics. This study focused on the relationship among a high risk course, low success rates, and attribution by examining the difference in the attributions passing and failing students gave for their performance in College Algebra.

The methods for the study included a pilot administration of the Causal Dimension Scale (CDSII) which was used to conduct reliability and principal component 
analyses. Then, students $(n=410)$ self-reported their performance on an in-class test and attributed their performance along the dimensions of locus of causality, stability, personal controllability, and external controllability. They also provided open-ended attribution statements to explain the cause of their performance. The quantitative data compared the passing and failing groups and their attributions for performance on a test using One-Way ANOVA and Pearson chi square procedures. The open-ended attribution statements were coded in relation to ability, effort, task difficulty, and luck and compared using a Pearson chi square procedure.

The results of the quantitative data comparing passing and failing groups and their attributions along the dimensions measured by the CDSII indicated statistical significance in locus of causality, stability, and personal controllability. The results comparing the open-ended attribution statements indicated statistical significance in the categories of effort and task difficulty. 


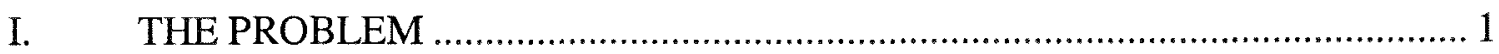

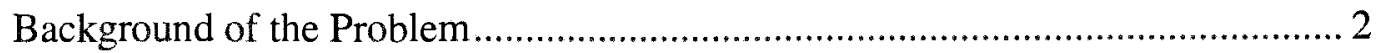

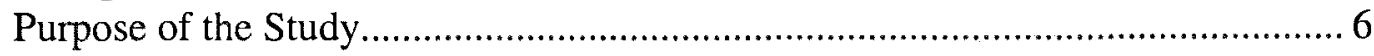

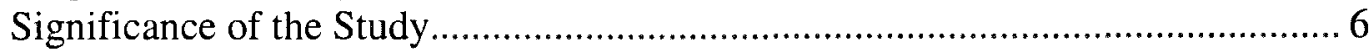

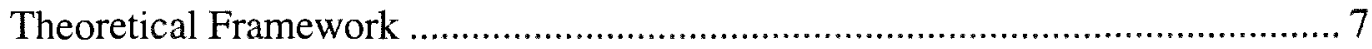

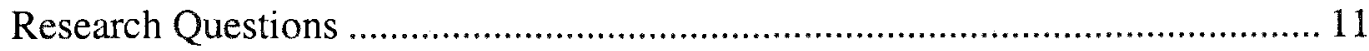

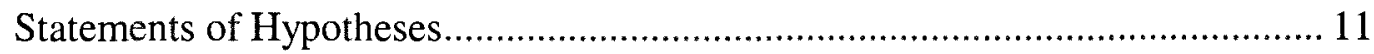

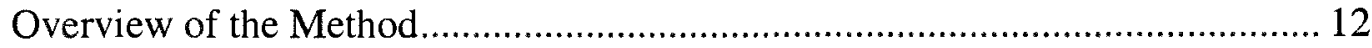

Organization of the Remaining Chapters ....................................................... 13

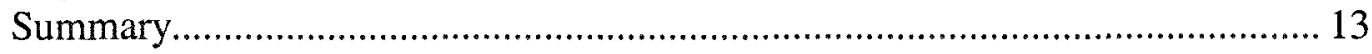

II. REVIEW OF THE RELATED LITERATURE ……...................................... 15

Attribution Theory and Academic Achievement............................................. 15

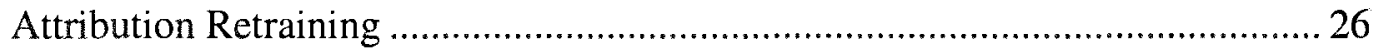

Self-Efficacy and Academic Achievement..................................................... 27

Locus of Control and Academic Achievement..................................................... 31

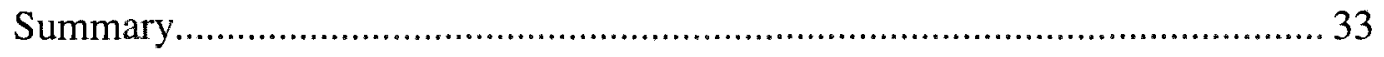

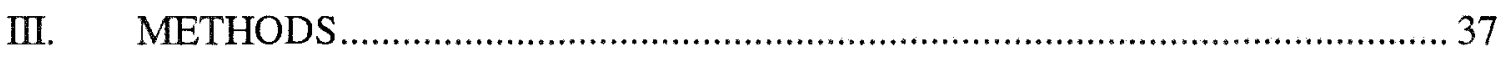

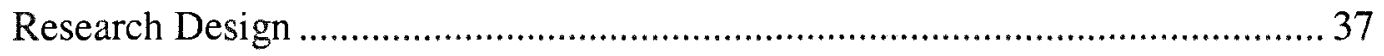

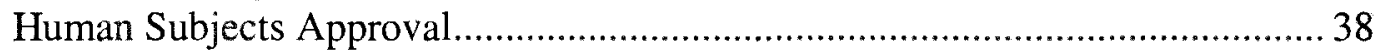

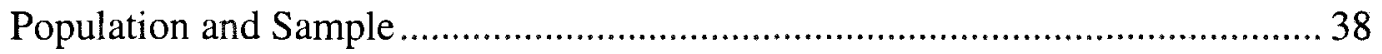

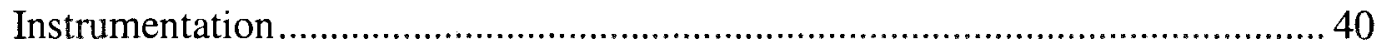

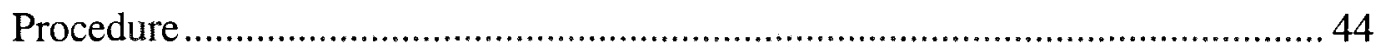

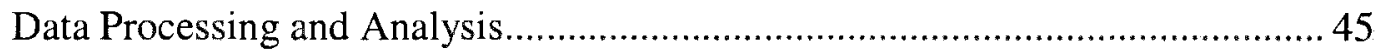

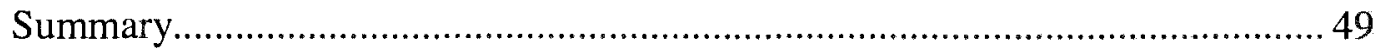

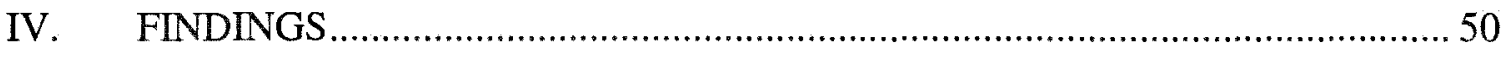

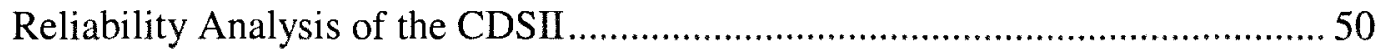

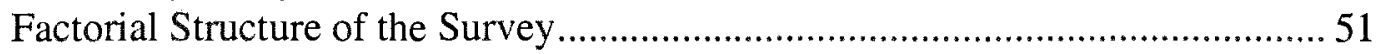

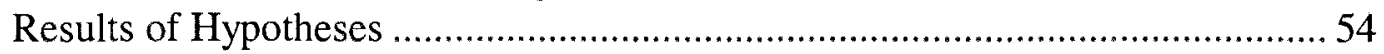

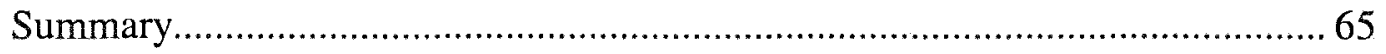




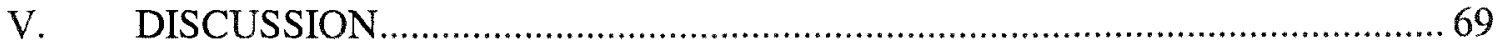

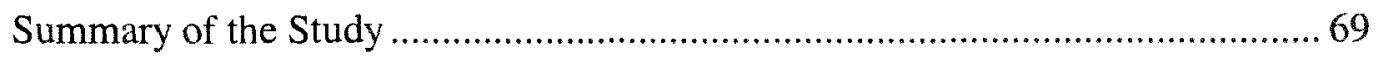

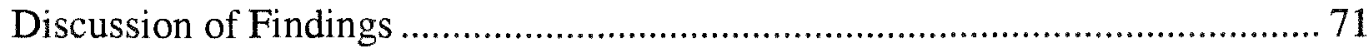

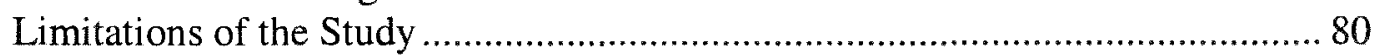

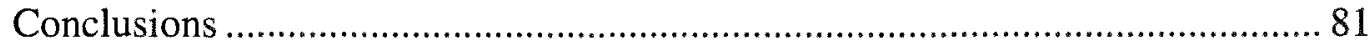

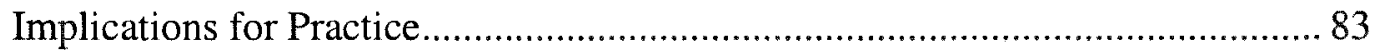

Recommendations for Future Research....................................................... 83

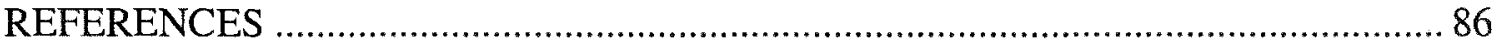

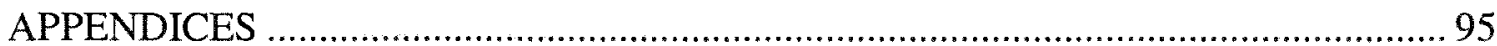

VITA 


\section{LIST OF TABLES}

TABLE

PAGE

1. Causal Dimensions and Their Related Attributions.....................................

2. MAC 1105 Student Profile for Spring Term $2004(N=4,691) \ldots \ldots \ldots \ldots \ldots \ldots . . . .40$

3. Relationship Between CDSII Items and Weiner's Attribution Categories ....41

4. Causal Attributions and Their Corresponding Items on the CDSII .............43

5. Coding of Attributions Among Factors ....................................................48

6. Reliability of the Four Causal Attribution Dimensions of the CDSII...........51

7. Factors and Loadings for the Scores of Causal Attributions Using Orthogonal

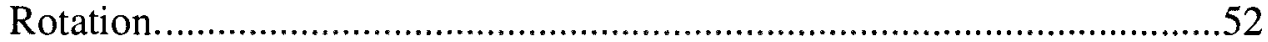

8. Factors and Loadings for the Scores of Causal Attributions Using Oblique

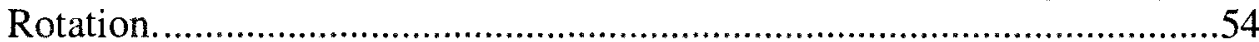

9. Means and Standard Deviations for Locus of Causality ...............................56

10. Means and Standard Deviations for Stability .........................................57

11. Means and Standard Deviations for Personal Controllability........................58

12. Means and Standard Deviations for External Controllability ........................58

13. Summary of Means Across Pass/Fail Groups ...............................................59

14. One-Way ANOVA Summary Table for Locus of Causality by Pass/Fail ......60

15. One-Way ANOVA Summary Table for Stability by Pass/Fail ......................60

16. One-Way ANOVA Summary Table for Personal Controllability by Pass/Fail

17. One-Way ANOVA Summary Table for External Controllability by Pass/Fail

18. Pass/Fail Groups and Open-Ended Attribution Statements .........................64

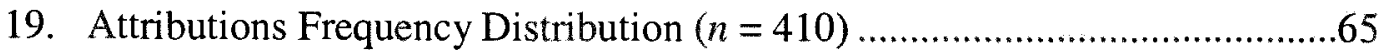




\section{CHAPTER I}

\section{THE PROBLEM}

College Algebra has become a key "gateway course" within the undergraduate general education curriculum. It has also been a focus of attention and a tough educational problem for colleges and universities due to its low success rates (Morris, 2002). The Council for Education, Policy, Research, and Improvement (2002) reported that success in mathematics continues to be a predictor of baccalaureate degree completion. This poses a particular challenge at the community college level where an open admissions policy allows students with academic deficiencies to enroll. This study was conducted at Miami Dade College, a large urban, diverse multi-campus college. One of the problems the institution faces is that many students who apply for admission at the College come underprepared for college level coursework. This is especially true in mathematics. For a number of years the College has been concerned with the continuation rate in mathematics progression. Students who place into remedial or college-level mathematics courses based on their scores are more likely to pass than those students who successfully complete the prerequisite course (Bashford, 2002). During the Fall Term 2003, only $18 \%$ of incoming students who took the Computerized Placement Test (CPT), or who had scores from other standardized tests that are used to assess readiness for college, tested as college-ready (Miami Dade College, 2003).

Self-beliefs and attributions regarding success and failure are significantly related to achievement (House, 2003; Kivilu \& Rogers, 1998; McMillan \& Forsyth, 1981). College students facing academic failure are threatened with the harmful consequences that come with that failure and which may affect their self-esteem, confidence, and 
mastery of the academic material. Many students believe that effort is the key to their success and that failure is a result of lack of effort. Some students, however, distort reality by making excuses after a failing grade, such as "It was not really a failure" or "I am not interested in this." These types of statements represent denial on the part of the student. Still other students give external reasons for their failure and take little or no responsibility for their academic performance. This type of student usually attributes his/her failure to the difficulty of the academic task or the instructor. This study examined passing and failing students and the attributions they gave for their performance in College Algebra. The problem and its background, the purpose of the study, its significance, and its theoretical framework are discussed in this chapter. The research questions and hypotheses are also presented.

\section{Background of the Problem}

The education profession continues to question why some students successfully meet their educational outcomes as measured by educational institutions and the larger society and others do not. The discussion of this issue among cognitive psychologists has led to conclusions which indicate that student beliefs about their probability and causes for success and failure greatly influence their academic achievement. From this perspective, when students experience success and explain that success by their ability and/or effort, they will most likely believe that ability and effort are most important to success, and that this is in fact under their control. Weiner $(1979,1986)$ suggests that the effort students put into their work can be explained by how they explain their successes and failures. His achievement-motivation theory provides one plausible explanation for the way students react to their academic performance. He believes that achievement- 
related tasks are routinely followed by self-evaluations of success or failure, which lead the individual into a cognitive search for an explanation of his or her performance. In an academic setting, this may lead the student to a question such as "Why did I fail the test?" Weiner further argues that when an individual attempts to explain his or her own success or failure, he or she is actually assessing personal level of ability, effort that was used for the task, or the difficulty of the task.

Attributions have been found to influence how individuals react to their successes and failures (Weiner, 1979, 1982, 1984). Attributions can be defined as the explanations and justifications individuals give for their success and failure. Attempts to reshape attributions may undo some of the harmful effects of failure (Forsyth \& McMillan, 1991; McMillan \& Forsyth, 1991). The research has suggested that attempts to change student attributions could aid in breaking the cycle of self-blame and therefore avoid further failure or poor performance (Wilson, Damiani, \& Shelton, 2002). Middleton, Spanias, and Photini (1999) believe that, in mathematics education, attribution theory is the theoretical orientation that makes most sense because (a) attribution theories are cognitive and describe the processes by which motivations are acquired and changed, and (b) they are applicable to a wide range of domains. Some researchers have found that attributions can be positively influenced through classroom instruction. Relich, Debus, and Walker (1986) studied the effect that attributional feedback had on achievement with a group of Australian students enrolled in an entry level mathematics course and found that when students are provided attribution retraining in conjunction with skills training, their mathematics achievement was positively affected. Other research indicates that a student will be first inclined to attribute failure to external factors and that this does not 
facilitate academic success (Forsyth, 1986). The literature reveals that students who succeed in their mathematics courses generally attribute their success to ability and effort and their failure to other factors (Amit, 1988). By the time students enter college, they have generally formed stable attributions regarding their success in mathematics. Since the attributional patterns of successful students who have chosen mathematics-related majors tend to be focused on ability and effort (internal causes), then students who may be attributing their failures to ability and effort may be systematically excluded from mathematics-related majors (Amit, 1988; Bassarear, 1986).

In other studies on attributions and their effect on academic achievement, it has been reported that students who habitually attribute poor academic performance to internal and stable causes are at risk of receiving poor grades during their first year of college (Barrett \& Peterson, 1987). Heller and Ziegler (2000), in their work on attribution retraining with female physics students, found that by altering attributional style, students were able to improve their academic performance.

American colleges and universities continue to be challenged by low success rates in College Algebra. This high enrollment course is considered a potential obstacle to student progress (Gilroy, 2002; Morris, 2002a; Singham, 2003). Although students believe that mathematics is important, the number of students who want to take more mathematics courses is steadily declining (Dossey, Mullis, Lindquist, \& Chambers, 1988). This can be an alarming fact when coupled with the fact that the majority of American college students do not possess the mathematics skills or knowledge to meet the nation's technological needs. This has so concerned the academic community, specifically the members of the mathematics discipline, that the National Council of 
Teachers of Mathematics has prominently placed the issues "Learning to Value Mathematics" and "Becoming Confident in One's Own Ability" on its agenda as an attempt to change the nature of mathematics teaching (National Council of Teachers of Mathematics, 1999). With its open-door admissions policy, the community college faces an even greater challenge in addressing the need to increase the success rate in College Algebra (Miami-Dade Community College, 2002; Morris, 2002a; Roueche \& Baker, 1987). Many students at the community college come underprepared for college level courses (American Federation of Teachers, 2003; Miami Dade College, 2004;

Morris, 2002b). At Miami Dade College, during the Fall Term 2003, only $18 \%$ of entering students who took the College Placement Test (CPT), or who submitted scores from other standardized tests used to assess college readiness, tested as college ready. Due to their large enrollments and attention given to underprepared students, community colleges have an increasingly important role in postsecondary education. For example, in Florida, the community college system enrolls twice as many high school graduates as the state university system (Council for Education, Policy, Research, and Improvement, 2002). Since achievement in College Algebra is required for college graduation, then, what does it take to improve academic performance in College Algebra? Perhaps what is important is not only understanding the reasons students are successful or unsuccessful, but also the process they go through in explaining their performance. Understanding the attribution process could provide another insight into academic achievement in College Algebra. 


\section{Purpose of the Study}

The purpose of this study was to examine the difference in the attributions students who passed and students who failed a College Algebra test gave for their performance on the test.

\section{Significance of the Study}

The attributions given by students following their self-reporting an actual grade received on an in-class test in College Algebra are presented in this study. This is in contrast with normal assumptions which are based on students reporting perceived grades. The use of self-reports of actual test grades implies that students in the study were presented with the opportunity to react to an actual grade rather than an estimate of their performance. Attributions as measured by this study are general and not academically related.

The results of this study provide data that may be useful for the development of intervention and academic support programs designed for college students challenged by College Algebra.

The findings of this study could be further significant in providing data that will help shape recruitment efforts for mathematics-related fields. As Miami Dade College continues to review and revise strategies that improve student success in College Algebra, it could use the results of this study as a basis for assessment and intervention programs. The findings of this study could provide the foundation for the design of intervention programs in College Algebra that focus on changing the way students attribute the causes of their academic success or failure. 


\section{Theoretical Framework}

Research in the field of attribution theory and academic achievement suggests that a relationship exists between a student's attributional style and achievement. Attribution theory is one of many possible cognitive methods to approach academic achievement. This approach neither invalidates or supersedes other cognitive approaches but it does provide one more way of understanding how individuals explain and react to their performance. Since attribution theory falls within the general construct of general theory, it can be equally applied to laboratory, clinic, or classroom settings.

Attributional style is a cognitive personality variable that reflects the manner in which individuals explain the causes for the successes and failures in their lives (Peterson \& Seligman, 1984). Several researchers who have studied academic achievement have reported that one of the most successful predictors of academic achievement has been attributional style (Bar-Tal, 1978; Diener \& Dweck, 1988; Fennema, 1977; Henry, Martinko, \& Pierce, 1993; Kloosterman, 1984, 1988; Wolleat, Pedro, Becker, \& Fennema, 1980). Although these studies focused on the dimensions of optimism and pessimism in relation to attributional style, they provide a framework for understanding the relationship between attributions and academic performance.

Studies by Wilson and Linville $(1982,1985)$ were based on the reasoning that in the first year of college students might encounter a series of academic setbacks common to the transition from one level of schooling to another, such as more challenging courses, and a new social environment. The way in which students explain these academic shortcomings is considered crucial. Students who blame their academic difficulties on internal, stable factors are likely to experience anxiety, put forth lower effort, and thus 
have difficulty in learning new material. Dweck (1975) indicated that encouraging students to attribute their poor performance to unstable causes resulted in both improved effort and performance. She reasoned that students who view their intelligence as a stable trait react to failure very differently than students who view their intelligence as unstable. Dweck's research was based on attribution theory.

Attribution theory has its roots in social psychology. In the early 1970s, Weiner developed an attribution theory of achievement motivation that served as the foundation for subsequent research in the field. According to Weiner (1974), attributions for success and failure on achievement-type tasks fall into four categories: effort, ability, task difficulty, and luck/chance. He said that these attributions are based on three constructs that he called causal dimensions: locus of causality, stability, and controllability (Weiner, 1985). The locus of causality dimension indicates whether the cause is internal or external to the subject. The attributions of ability and effort can be said to fall within the internal dimension. However, the attributions of task difficulty and luck fall within the external dimension. The stability dimension refers to whether the cause is invariant or changeable over time. In this dimension, task difficulty is a stable cause, whereas luck and effort are conditions that change over time. Finally, the controllability dimension reflects whether the cause is personally or externally controllable or uncontrollable. In this last dimension, effort may be determined to fall under the personal control of the individual, while ability, task difficulty, and luck may be seen as externally controllable. Covington (1992) suggests that the dimension of controllability is distinguished by the characteristic of intentionality that he describes as whether or not a cause is subject to the 
individual's deliberate control. Table 1 presents the causal dimensions of locus of causality, stability, and controllability, their parameters, and relationship to attributions. Table 1

Causal Dimensions and Their Related Attributions

Causal Dimension

Locus of Causality

Stability

Controllability
Parameters

Internal

External

Invariant

Changeable

Personal

External
Attributions

Ability/Effort

Task Difficulty/Luck

Task Difficulty

Effort/Luck

Effort

Task Difficulty/Luck

Russell (1982) discovered that the typical attribution paradigm did not allow for variations in the way individuals perceive the causes of their successes and failures. In the traditional approach used to assess causal dimensions, researchers have generally translated the causal attributions made for an achievement-type task by the subject into the causal dimensions described by Weiner (1985). This assumes that the researcher perceives causes in the same way as the respondent. Russell found this methodology problematic since it did not take into consideration that a meaning of an attribution could vary greatly from person to person and from situation to situation. In an effort to address this issue he developed the Causal Dimension Scale, a psychometric instrument designed to measure how the individual perceives the causal attributions he or she has given to 
performance on an achievement-type task. In other words, the respondents are given the opportunity to indicate directly how they view the attribution in terms of the causal dimensions of locus of causality, stability, and controllability (Russell, 1982; Russell, McAuley, \& Tarico, 1987). The locus of causality dimension is defined as referring to whether the cause was something about the attributor (internal) or outside the attributor (external); the stability dimension is defined as referring to whether the cause was constant over time (stable) or variable over time (unstable); and finally the dimension of controllability allows for both internal and external causal factors. Therefore, a controllable cause is defined as one that could be affected by someone, either the attributor or others (Weiner, 1979).

Dweck (1975) was one of the first researchers to argue that encouraging individuals to attribute poor performance to unstable causes could improve future effort and performance. She went on to develop a model that emphasizes people's theories about their own intelligence. She theorized that those people who view their intelligence as fixed or stable are hypothesized to react to failure differently than people who view their intelligence as a changeable skill and are more likely to give up, believing that they do not have the skill required for the task. Dweck (1999) continued to frame her research within attribution theory when she argued that individuals who view their intelligence as stable are likely to attribute academic failure to an internal, stable cause (low intelligence that will not change); whereas individuals who attribute academic failure to an external, unstable cause believe that they may not have the necessary skills but that they can be acquired with increased effort. She concludes that the best way to change attributions is to address these theories, rather than specific attributions. 


\section{Research Questions}

College students provide causal attributions when they succeed or fail in an achievement-type task. These attributions can be classified into the following dimensions: (a) locus of causality, (b) stability, (c) personal controllability, and (d) external controllability. It is important to determine if there is a difference in these attributions between students who pass or fail a College Algebra test. Therefore, the following five research questions were developed:

1. Is there a difference in the locus of causality dimension between students who pass and students who fail a College Algebra test?

2. Is there a difference in the stability dimension between students who pass and students who fail a College Algebra test?

3. Is there a difference in the personal controllability dimension between students who pass and students who fail a College Algebra test?

4. Is there a difference in the external controllability dimension between students who pass and students who fail a College Algebra test?

5. Is there a difference between students who pass and students who fail a College Algebra test and the open-ended attribution statements they give for their success or failure?

\section{Statements of Hypotheses}

The hypothesized responses to the questions are:

1. Students who pass the College Algebra test will attribute their performance on the test to internal causes. 
2. Students who pass a College Algebra test will attribute their performance on the test to stable causes.

3. Students who pass a College Algebra test will attribute their performance on the test to causes under their personal control.

4. Students who pass a College Algebra test will attribute their performance on the test to causes which others cannot control.

5. Students who pass a College Algebra test will give open-ended attribution statements of ability and effort to explain their performance on the test.

\section{Overview of the Method}

The study was conducted at a large, urban, multi-campus community college with a diverse student body. Four hundred and ten community college students enrolled in College Algebra during the Spring 2004 Term made up the sample for this study. Twenty-four sections of College Algebra were randomly selected by the institution's Office of Institutional Research in order to create the sample group. The Revised Causal Dimension Scale II (CDSII) was administered to measure how students attributed their performance on a College Algebra test.

The two groups in this study were created using a grade on the first in-class algebra test of the semester. Students receiving a grade of $75 \%$ or higher were included in the group of students who passed, and students who received a grade of $74 \%$ or lower were included in the group of students who failed. Prior experience of faculty teaching College Algebra has determined that students who earn a grade of $75 \%$ or higher on the first test of the semester have a much higher probability of successfully completing the course (P. Bibby, personal communication, November 14, 2003). In order to conduct 
further analyses, a top one-third group was identified, defined as those students selfreporting a test grade of $67-100$, and a bottom one-third group was identified, defined as students self-reporting a test grade of $0-33$ on the College Algebra test.

In order to address the reliability and validity of the survey instrument, principal component and reliability analyses were conducted. A One-Way Analysis of Variance (ANOVA) was applied to test for a significant difference between the groups. Pearson chi square tests for differences in proportions were calculated to test for differences in the attributions given by students in the top one-third and bottom one-third groups and in the open-ended attribution statements given by both the passing and failing groups. A detailed explanation of the methods and procedures are provided in Chapter III.

Organization of the Remaining Chapters

In Chapter II attribution theory is discussed as it relates to academic achievement. It also examines the research on causal attributions for success and failure within the context of achievement and particularly mathematics achievement. The sample for the study and the methods used to collect, organize, process, and analyze the data are described in Chapter III. The findings of the statistical analyses applied to the data are reported in Chapter IV. Finally, a discussion of the results, presentation of the conclusions and implications, and recommendations for future research are found in Chapter V.

\section{Summary}

Success in mathematics has been identified as an indicator of baccalaureate degree completion. Within the mathematics coursework, College Algebra has been determined to be a "high risk" course due to its low level of success. This distinction 
within the general education curriculum has defined College Algebra as an obstacle to program and degree completion.

Literature in the field of attribution theory suggests a relationship between the way students explain the causes of their academic performance and academic achievement. Studies have reported that attributions can influence how individuals react to success and failure on achievement-type tasks. Some studies have concluded that attribution re-training has an effect on academic performance. This could prove to be of great significance to efforts toward the improvement of success rates in College Algebra.

The work of Weiner $(1979,1982,1986)$ on attribution theory provided the theoretical framework for this study. Weiner's identification of the causal dimensions: locus of causality, stability, and controllability served as the foundation for the Revised Causal Dimension Scale II (CDSII). This survey instrument that measures how individuals perceive their causal attributions for performance was administered to College Algebra students in a community college setting. The study was designed to examine the difference in the attributions passing and failing students gave for their performance on a College Algebra test. 


\section{CHAPTER II}

\section{REVIEW OF THE RELATED LITERATURE}

The relationship between academic performance in College Algebra and how students attribute their performance in terms of causal dimensions as measured by the Revised Causal Dimension Scale II (CDSII) was examined in this study. The literature review addresses the work in the field of attribution theory, academic achievement, selfefficacy, locus of control, and attribution retraining. Finally, the theory and empirical research of attributions as they relate to performance in academic settings are examined.

\section{Attribution Theory and Academic Achievement}

Substantial research on the nature of attributions in an academic setting is evident within the attribution literature. Since assessing student achievement continues to hold an important place in higher education, it is therefore important to understand how students respond to their academic performance. Their perception of whether they succeeded or failed, and an analysis of why they succeeded or failed, can have an effect on future performance.

Attribution theory has its foundation in social psychology growing out of the research on achievement motivation. The analyses of attributions within the framework of achievement behavior have usually included questions regarding the reasons for success or failure at some academic task. For example, a series of mathematics problems, an in-class test, a final examination, a final grade in a course, or grade point average have been analyzed in reference to their relationship to attributions. Most of the literature has examined how outcomes have been attributed to four causes: (a) ability, (b) effort, (c) task difficulty, and (d) luck. These causes were initially identified by 
Heider (1958) in his early work on the nature of attributions. His work generally analyzed the perceptions people have of others and how they explain those perceptions. It can be said that the history of attribution theory began with the study of Heider's person perceptions. He was an advocate of a phenomenological approach to the study of human behavior. This approach assumed that, in order to understand what people will do, one has to see the world through their eyes, specifically how people explain the reasons for their own behavior or the behavior of others. Heider suggested that, in general, people are constantly seeking causal explanations for the outcomes of their behavior. Heider categorized ordinary explanations as having either personal or environmental causes. He believed that people explain their actions by attributing the cause to either an internal or external factor. In his studies Heider analyzed in detail how people answer questions regarding the cause, purpose, and intent of their own actions and behaviors or that of others. His concern was with the way people handle everyday events and he concluded that events should be explained in commonsense terms. Although simplistic as an explanation and approach, Heider's theory served as a starting point for the field of attribution theory in social psychology.

Theorists in social psychology (Hilton, Fein, \& Miller, 1993; Jones, 1990;

Weiner, 1990) consider that the process individuals use to make judgments about the causes of behavior, especially when something unexpected or unpleasant occurs, is quite predictable. Attribution theory addresses the question of how individuals make these judgments. When an individual makes an attribution, he/she is usually guessing about the true cause of a particular action. When applied to academic achievement, the student may be attributing success and failure to various factors. 
Heider's theories proved to be the basis for the growing interest in the application of attributions within the field of social psychology. The work of Weiner was influenced by Heider and has been credited with having made a major contribution to the research on attribution theory. Weiner (1986) was among the first to extend attribution theory to the domain of academic achievement. Weiner's theories have proven to be most important to the academic community since his research focused on the understanding of the causes of success and failure in an academic setting. He theorized that if one can change people's attributions for poor performance to an unstable cause, such as low effort or bad luck, one can then raise their expectations about future performance. This led the way to studies which used intervention models based on attribution theory. Weiner further reasoned that the basic principle of attribution theory is a person's attempt to understand why an event occurred and to search for causes. He suggested that people are quite selective about the attributions they make. He explained that people are most likely to make attributions: (a) when unusual events attract their attention, (b) when events have personal consequences, (c) when others behave in unexpected ways, and (d) when they are suspicious about the motives underlying someone else's behavior (Weiner, 1990). As reported by Weiner and his colleagues (Weiner et al., 1972; Weiner \& Kukla, 1970), students who are successful explain their academic achievement in terms of ability and effort. They tend to explain failure by lack of effort or unstable factors that are external in nature. Ability is an internal, stable, uncontrollable factor. Effort is an internal, unstable, controllable factor. When one attributes success to ability and effort, it brings feelings of pride and continued expectations of success. When students attribute academic failures to lack of effort, it allows them to maintain a positive view of themselves as competent 
students because the level of effort that they put into the task was totally in their control. Students who experience failure and attribute that failure to lack of interest or to the limited time they were able to devote to the task can maintain positive views of themselves as competent students by explaining that they could have been successful if they had been interested in the task and/or had spent the effort necessary for success.

A research study conducted by Bernstein, Stephan, and Davis (1979) asked 469 college students enrolled in an introductory psychology class at the University of Texas at Austin to describe the cause of their academic performance after an examination. They found that successful students felt effort and ability were more important to them as they explained their performance, whereas they considered test difficulty and luck to be less important. They also reported that the single most important factor students used to explain their performance was their perceived amount of study. This highlights the important role of effort in the attribution process. A study by Kovenkliouglu and Greenhaus (1978) assessed the reactions of college students enrolled in a chemistry course when informed of their grade on an in-class examination. The sample for this study was 253 freshman chemistry male students at Stevens Institute of Technology. The researchers excluded female students from the study based on their concern that attributional tendencies vary by gender and that only 45 female students were registered in the class. They indicated that approximately $80 \%$ of the students were engineering majors and the vast majority of the remainder majored in science. They found that students who perceived their academic performance as successful attributed that success to ability and effort, an internal/stable attribution. However, students who perceived their academic performance as a failure related their grade to effort, an internal/unstable 
attribution. The limitations of the Kovenkliouglu and Greenhaus study as posed by the sample indicate a need to examine the attribution process using a more diverse sample as this study provides. Both of these studies suggest that stability was the principal characteristic of attributions that defined how successful and failing students explained their academic performance. These studies were also strongly influenced by Weiner's typology regarding attributions and achievement.

Covington and Omelich (1979) in their work on attributions and student achievement, maintain that attributing either success to effort or failure to lack of effort can be problematic. They reason that when students expend the effort and are successful, it brings them a sense of accomplishment and pride. However, if they have to put in an extraordinary amount of effort in order to be successful, it may imply that they have lower ability than other students who can successfully complete the task with less effort. They explain that students who believe they lack the ability to be successful at a given task may not be willing to put in the effort needed because failure would be a public admission of low ability. They further note that when a student does not try and subsequently fails, the student may not consider this as really failing because to him/her true failure happens only when one tries hard to accomplish a task and fails to do so. Covington and Omelich believe that giving the cause for the failure as lack of effort is an attempt on the part of the student to protect and preserve a sense of self-worth.

In his work with adolescents, Nicholls (1984) reports that adolescents define high ability in relation to others. Adolescents, he concludes, consider that high ability requires that little effort is given to a task. For many adolescents, having to put forth a great deal of effort in order to accomplish an academic task is evidence of low ability. When 
testing the hypothesis that college students would choose to spend less effort in order to attempt to convince other students that lack of effort rather than low ability explained their lack of success, Jagacinski and Nicholls (1990) found that college students did not see the reduction of effort as a viable personal strategy, but the students thought that other students would in fact use that strategy. Their study, conducted with 123 students enrolled in an introductory psychology course at Purdue University, found that when students expected a failure that pointed to their incompetence, they intentionally reduced effort so that the failure could be attributed to low effort, rather than to low ability. They noted that trying to use this strategy of low effort to explain one's failure meant that the person employing the strategy has to be willing to acknowledge low ability as the cause of poor performance. Therefore, they reasoned, the relationship between effort, success, and self-worth is a complex one.

Attribution theory is also concerned with the relationships that exist between attributions and other motivational variables. Abramson, Garber, and Seligman (1980) contend that attribution theory suggests that performance, which is consistent with the expectations of the individual is attributed to stable causes. However, performance which is not consistent with the expectations of the individual is attributed to stable or unstable causes. In general, it is believed that this holds true whether the performance outcome is success or failure. In the context of academic performance, it has been reported that when students do not perform well on achievement-type tasks, they make causal attributions for their lack of success (Weiner, 1986). These attributions, therefore, affect their expectations of any future performance and greatly depend on the type of attribution that is made. For example, when a student attributes failure to an internal/stable cause such as 
ability, it is predicted that the same outcome can be expected on future achievement-type tasks. On the other hand, if the student attributes failure to internal/unstable causes such as effort, the student may believe that this may change in the future, and thus does not expect failure on future tasks (Kloosterman, 1988).

Other research on attributions posed more complex views. Platt (1988) provided clarification regarding the complex relationship between attributions and achievement in an actual classroom setting. Platt used covariance structural modeling to test a causal model representing the relationships among causal attributions, intervening variables, and achievement. He assessed the attributions students made regarding their high school success or failure. Expectancy of success in college, predicted level of effort, academic self-concept, and aptitude were also measured. Platt's study with freshman engineering students reported that those who attributed their success in high school to high ability and effort were more likely to expect success in college. He also found that the attributions these students made for their success in high school predicted effort and academic selfconcept in college. Although Platt's work was limited to an analysis of performance during the first term of college, it contributes to the work on attributions in academic settings and highlights the long-term effects that past attributions can have on future success and failure.

In their study on causal attributions and perceived performance, Perry and Magnusson (1989), examined the typical causal attributions that students have for their failures as described by Weiner $(1979,1986)$. They identified those as being ability, effort, and task difficulty. Their research was based on Weiner's theory that causal attributions and ensuing failure feedback on a test were expected to influence the 
students' perceived control and achievement in subsequent academic tasks. The study which involved 223 female and male college students enrolled in an introductory psychology class at the University of Manitoba, found that perceived success, when no success was evident, was associated with lower achievement and that perceived failure, when there was no failure evident, was also associated with lower achievement. They concluded that the usefulness of utilizing causal attributions to better understand academic achievement may largely depend on the student's interpretation of failure.

Russell, McAuley, and Tarico (1987) conducted a study to evaluate the reliability and validity of the original Causal Dimension Scale (Russell, 1982). The participants in the study, 71 men and 90 women college students enrolled in an upper-division psychology course, completed the Causal Dimension Scale in order for the researchers to assess how the students perceived the cause of their success or failure on an achievementrelated task along the dimensions of locus of causality, stability, and controllability. Of particular importance to this study was the second measure that was conducted as part of the study. The open-ended attributions that students were requested to give were coded and tabulated along the dimensions of locus of causality, stability and controllability. A frequency of the causal attributions was then conducted and the results indicated that the most frequent attribution given for failure was in the category of unstable effort (i.e., "did not study"). The ease or difficulty of the examination was reported as having the second most frequent attribution, followed by ability.

Winn (1995) examined the differences between the attributions of college students on academic probation who were successful and those who were unsuccessful during their probationary semester. The study was conducted with 73 students at a 
university in northwestern Oklahoma. The Revised Causal Dimension Scale (CDSII) was administered. Winn found no significant differences between the successful and unsuccessful groups on the four subscales of the CDSII. She reported, however, that unsuccessful females were significantly more external in their attributions for failure than were the unsuccessful males and concluded that as achievement behaviors increase in females, male/female differences decrease.

When discussing the motivation for achievement in mathematics, Middleton and Spanias (1999) indicate that of all the theoretical orientations surrounding academic achievement, attribution theory is the most widely accepted because (a) attribution theory is cognitive, and (b) it is applicable to a wide range of domains. As one looks at the academic history of most students, it is generally accepted that students in the lower elementary grades are highly motivated to learn mathematics. Kloosterman (1993) reports that many first and second graders believe that they are competent and that working hard will bring them success. He found that students at this grade level do not distinguish between effort and ability as causes of success in mathematics. However, by the middle grades, many students begin to see mathematics as the special domain of smart students and that others merely get by or fail. They begin to believe that success and failure in mathematics are attributes of ability and that effort does not generally result in success (Kloosterman \& Gorman, 1990). In earlier research with seventh graders, Kloosterman (1988) investigated how these students perceived the role of success and failure in influencing their attributions, their mathematical self-confidence, their beliefs about effort as a mediator of mathematical ability and their acceptance of failure as a normal phase in learning mathematics. His study of 266 female 223 male seventh-grade 
students from three lower-middle to upper-middle class schools in south central Indiana, found that attributional style was the best predictor of mathematical self-confidence, as indicated by the data which showed that attributional style accounted for $17 \%$ of the variance in mathematics self-confidence, while effort as a mediator of mathematics ability accounted for only $8 \%$. He also reported that mathematics students made relatively more attributions in reaction to failure as opposed to success. The belief that effort served as a mediator of ability and that failure was an acceptable phase in learning mathematics were also contributors to the mathematics self-confidence of students. Although these findings contribute to understanding and conceptualizing the attribution process in a mathematics setting, they are limited by the lack of diversity of the sample as $90 \%$ of the students in the study were reported to be White.

Meyer and Fennema (1985) examined the relationship between students' attributions of success in mathematics in the eighth grade and their eventual achievement in the eleventh grade. They found that attribution of success to ability was the most evident in eleventh grade students who were achieving. Similarly, attribution of failure to lack of ability was the most evident in all students who were not achieving. They also found that those students who attributed failure to lack of effort also showed low achievement in computation problems and high level conceptual mathematics tasks.

By the time students reach college they have generally formed some rather stable attributions regarding their success in mathematics (Amit, 1988; Bassarear, 1986). When studying the attributions of university students, Amit (1988), found that overall, female students tended to attribute their success in mathematics to external and unstable causes, and that male students attributed their success in mathematics to ability, which is 
considered an internal and stable factor. However, when the study was conducted within academic majors, students tended to attribute their causes of success and failure in mathematics the same way regardless of gender. Those students choosing mathematics as a major tended to attribute their success to ability and failure to other factors. In fact, the researcher concluded that as the mathematical requirements for participation in particular majors increased, so did the attribution of success to the internal factor of ability. As a result of this study, Amit reasoned that students who attribute their failures in mathematics to internal factors and their success to external factors are unlikely to choose a college major which requires a substantial mathematics content.

Also revealed in the literature is the insignificant role that gender plays in attributional style (Campbell \& Henry, 1999). Their research on the relationship between gender and self-attributions, attributional consistency, style, and expectations for performance in a college mathematics course, reported that both genders demonstrated consistency over time and that there was no difference in specific attributions for course performance by gender combined with accuracy in predicting performance.

Within the context of remedial mathematics, Bassarear (1986) attempted to identify a set of affective variables, including students' beliefs about mathematics and about learning mathematics, that could possibly predict achievement. Using this setting he gathered data from 145 college students enrolled in a basic mathematics course at the University of Massachusetts at Amherst. Attitudinal data were gathered through the use of a questionnaire, essay questions, and interviews. The mathematical ability of students was assessed with two diagnostic tests. Bassarear obtained data on eleven attitudes, 
including: a) level of anxiety, b) perceived usefulness of mathematics, c) confidence in learning mathematics, d) predicted grade, e) attributions for success and failure, and f) four measures of students' beliefs about learning mathematics. Significant $(p<.01)$ Pearson correlations were found between performance in the mathematics course and measures of ability, predicted grade, and attributions for success.

\section{Attribution Retraining}

In further studies on attribution and academic achievement it has been reported that students who habitually attribute poor academic performance to internal/stable causes are at risk of poor grades during their first year of college (Barrett \& Peterson, 1987). There have been a number of attempts to use the principles of attribution theory as an intervention strategy for low performing students. Heller and Ziegler (2000), in their work on attribution retraining, found that by altering attributional style, students were able to improve their self-concept as it related to their ability and therefore improve their academic performance. Some attribution retraining programs have been developed to teach students that effort rather than ability can determine academic success (Fosterling, 1985). Wilson, Damiani, and Shelton (2002) in their review of studies that focused on attribution retraining, report that attribution retraining is an effective and inexpensive strategy for improving academic achievement. Skinner (1996) suggests that when one attempts to improve attributions, it is important to determine if the set of beliefs one needs to change are causal beliefs, as implied by attribution theory, or beliefs related to self-competence, as implied by efficacy theory. This observation may indicate that successful attribution retraining programs must be designed to change specific beliefs such as the level of effort that will determine academic success or failure. 
Wilson and Linville (1982) based their work using attribution therapy to improve the performance of college students. They argued that encouraging people to attribute their poor performance to temporary causes should increase their expectations regarding their future performance, reduce their anxiety and feelings of helplessness, and lead to better performance. Their study was conducted with a group of college freshmen who had expressed concern regarding their academic performance. They agreed that convincing these students that their academic problems were temporary rather than permanent had a beneficial effect. They reported that students in the study improved their performance by (a) improving their performance on sample GRE items, and (b) improving their GPA one year after completion of the study. This resulted in a lower percentage of students who left college after their first year. One of the positive influences of attribution retraining is that it allows students who are not achieving to reduce their feelings of defeat. Relich (1984) argues that when students are provided with programs of attribution retraining in combination with skills training, their feelings of defeat are reduced and their mathematics achievement is positively affected. He proposed a causal model that contrasted the direct effects of attribution retraining with the effects of achievement and defeat. Results of his study indicated that although attribution retraining had a moderate effect on achievement, it increased self-efficacy.

\section{Self-Efficacy and Academic Achievement}

Another area of research which provided a foundation for this study considers student characteristics and their effects on academic achievement. The concept of selfefficacy was developed by Bandura in the late 1970s and is a major component of his social-cognitive theory, which explains that behavior is strongly stimulated by self- 
influence (Bandura, 1986). This becomes particularly important as one attempts to understand how students behave and explain their academic achievement. Since the focus of this study is to examine the explanations students give for their success or failure in an academic setting, the concept of self-efficacy and how it relates to the way students attribute their academic performance is of relevance. Bandura has defined self-efficacy as "people's judgments of their capabilities to organize and execute courses of action required to attain designated types of performances" (1977, p. 391). Bandura's theory is based on two premises. First, students interpret their past successes and failures and set goals based on those interpretations. According to Bandura, people in general tend to avoid those situations they believe exceed their level of ability, but take on and perform with assurance those tasks that they have judged they can accomplish successfully. Second, when students set their goals, those goals become their personal standard for evaluating their performance. He further reasons that the reward for attainment of goals is self-satisfaction. Therefore, committing the effort it takes to attain those goals is how people avoid their disappointment with poor performance. According to Bandura, internal rewards for goal attainment can have a more powerful influence on effort and achievement than external rewards such as grades. Bandura has determined that people develop their self-efficacy from four sources: (a) performance accomplishment, (b) observation of the performance of others, (c) verbal persuasion and related types of social influence, and (d) states of physiological arousal from which they judge their personal capabilities and vulnerability (Bandura, 1982). He further explains that when students master a task, it increases their expectations that they will master similar tasks in the future. 
House (2001), in his research on student characteristics and academic achievement, looked for cognitive-motivational predictors of achievement for undergraduate students majoring in health sciences. He used the premise that students who select the health sciences as a major enroll in courses which pose a greater degree of difficulty, especially mathematics. He concluded that a student's self-belief and academic background were significantly related to academic achievement. How the students rated themselves in terms of their general and mathematical ability were also significant predictors of their performance. Wood and Locke (1987) further explored the concept of self-efficacy in the context of undergraduate students. The result of their research shows that when ability is controlled, academic self-efficacy clearly contributes to academic performance. They also concluded that greater self-efficacy leads to the pursuit of higher personal goals which results in higher academic achievement. Cantrell (2001) examined the relationship between self-efficacy, causal attribution, self-esteem, and academic success with a group of 264 nursing students in their junior and senior year at a southeastern university. Her findings indicate that, overall, students attributed their success or failure to factors that were internal, over which they had control, and which were relatively stable. She reported significant positive bivariate correlations for most of the measures, with the exception of academic success. Academic success was significantly correlated only with stability. Cantrell concluded that although high selfefficacy, causal attributions linked to academic success, and high self-esteem will not guarantee success in nursing programs, low self-efficacy, causal attributions linked to unsuccessful academic performance, and low self-esteem may be barriers to success for 
some students in nursing programs. This relationship between self-efficacy and causal attributions is of importance to this study.

Although success generally contributes to enhancing efficacy expectations, the attributions of success to ease of the task or help from others may not lead to increased efficacy expectations. This means that for efficacy expectations to be enhanced by success, that success must be attributed to ability or effort. When applying the selfefficacy construct to the classroom, Tollefson (2000) reports that students develop beliefs regarding their efficacy associated with their academic experience. As students receive feedback for their performance in class, some students may begin to change their selfefficacy expectations to believe that, while it is possible to be successful in class, they personally do not have the skills, abilities, and/or work ethic to be successful. She further suggests that students who have expectancies regarding their performance and low selfefficacy expectancies may begin to decrease their effort over the course of time. However, some students who may enter the classroom with low expectations regarding their performance do not believe that effort will lead to success.

In an attempt to further define self-efficacy, Mitchell, Hopper, Daniels, George-Falvy, and James (1994) concluded that it "clearly refers to what a person believes he or she can do on a particular task" (p. 506). Self-efficacy in an academic setting has been operationally defined as a student's degree of confidence in performing various achievement-type tasks (Solberg, O'Brien, Villareal, Kennel, \& Davis, 1993). Self-efficacy is particularly applicable to the study of academic achievement of college students and is supported by the sources of self-efficacy expectations as described by Bandura (1986): mastery, vicarious persuasion, and physiological feedback experiences. 
These can be easily incorporated within programs in higher education aimed at improving academic performance.

Russell and Petrie (1992) reported that a number of academic, social/environmental, and personality factors must be considered when one is evaluating college academic achievement. They also indicate that the academic adjustment of college students can be organized according to three factors: (a) academic performance, (b) social adjustment, and (c) personal adjustment. They suggest that self-efficacy expectations are an important factor in the promotion of personal adjustment among college students. A number of studies support this opinion that perceived self-efficacy in a certain area influences academic achievement (Gist, Schwoerer, \& Rosen, 1989; Hill, Smith, \& Mann, 1987; Taylor, Locke, Lee, \& Gist, 1984). Locke and Latham (1990) have determined that individuals with high self-efficacy tend to pursue challenging goals, do their best, see new solutions, and persevere when completing difficult assignments and tasks. This type of behavior may lead to the development of actual ability and to the eventual achievement of goals. They also report that individuals with low self-efficacy pursue lower levels of performance.

\section{Locus of Control and Academic Achievement}

Social learning theory also points to locus of control within personality theory. Rotter (1971) notes that two personality types exist: (a) people with an internal locus of control who perceive that reinforcement is due to their own behavior, and (b) people with an external locus of control who perceive that reinforcement is independent of their behavior and dependent on factors that they cannot control. In his work as a psychotherapist and researcher, Rotter, treating his patients' persistent, self-defeating 
actions with standard behavioral principles, found that these methods were not successful. He discovered that his patients had developed entrenched attitudes as a result of their life experiences and that these attitudes were affecting their decision-making abilities and their actions (Rotter, 1982, 1990). In order to measure locus of control, Rotter developed an Internal/External (I/E) Scale. This Scale determines that people who feel personally responsible for the things that happen to them are internals and people who feel that their outcomes in life are determined by forces beyond their control are labeled externals. Studies that used this scale have provided conclusions that an internal locus of control emerges at an early age and is associated with many aspects of life such as health, academic achievement, and political activism (Nowicki \& Strickland, 1973; Strickland, 1989). Findley and Cooper (1983) suggest that most people fall somewhere in the middle of the two extremes and that locus of control is a relatively stable characteristic, although it can be modified through experience. This work relates to Weiner's three-dimensional theory which classified the locus of control characteristic into two dimensions: locus, referring to the internal/external dimension; and control, referring to the degree of personal or external control. These dimensions are examined in this study.

Locus of control, in terms of the beliefs of the individual, has been studied in a number of contexts and has received a great deal of attention in the context of achievement and achievement-type tasks. Internality and its relationship to greater achievement have been studied in various settings. An important setting, and one that is relevant to this study, is education. Biggs (1987) investigated a relationship between locus of control and the study skills of undergraduate college students. She reported that 
students with the most advanced study skills tended to have an internal locus of control, individualistic tendencies, higher perceived scholastic competence, higher self-worth, and higher perceived intellectual ability. Biggs also indicated that for students to be able to use certain learning strategies in an effective manner, they must have both internal locus of control and high ability. Her study with 202 college students enrolled in an introductory psychology course at a southeastern university provided evidence of a significant relationship between locus of control and current academic achievement and future performance. Locus of control was also reported to be a strong predictor of grade point average in a college setting. This means that having ability and an internal orientation can have greater impact on the student's ability to decide on how to approach an academic task. Another study by Kulas (1996) points to the fact that locus of control may not be a stable factor in students and that it may be affected by academic achievement. He describes that adolescence is a period of relative stability of locus of control, which implies that it is established earlier in life. He also reported that although he found no statistical significance, locus of control tends to shift and is related to academic achievement. He believes that this may be caused by temporary factors such as teachers or peers. He also indicates that the influence of grades on an adolescent's locus of control may greatly influence future plans and career choice.

\section{Summary}

The work of Heider (1958) on perceptions and how people explain those perceptions provided the foundation for the development of attribution theory. Weiner (1972, 1986), influenced by Heider's work, was among the first theorists in social psychology to extend attribution theory to the domain of academic achievement. This led 
the way to a number of studies that focused on the role attributions for success and failure play in academic settings.

Abramson, Garber, and Seligman (1980) contend that attribution theory suggests that performance, which is consistent with individual expectations is attributed to stable causes, and that performance which is not consistent with the expectations of the individual is attributed unstable causes. Attribution theory has also been widely accepted by researchers in the field of mathematics achievement (Middleton \& Spanias, 1999). Amit (1988) and Bassarear (1986) reported in separate studies, that by the time students reach college, they have generally formed rather stable attributions regarding their success or failure in mathematics. This study will build on this work as it examines the differences between the attributions made by passing and failing students in College Algebra.

In order to address the tendency of low-achieving students to form maladaptive attributions for their success and failure, various researchers have studied the uses of attribution retraining as an intervention strategy. Heller and Ziegler (2000) found that, by teaching students to alter the attributions they gave for success and failure, they were able to improve academic performance. Wilson, Damiani, and Shelton (2002) indicated that when attribution retraining is used as an intervention strategy for low achieving students, it can provide both an effective and inexpensive solution for academic support.

Another field of research which provided a foundation for this study is selfefficacy. The work of Bandura $(1982,1986)$ has presented self-efficacy in the context of academia as (a) how students interpret their past successes and failures and then set goals 
based on those interpretations and (b) how students set their goals and then those goals become their personal standard for evaluating performance.

The literature on attributions and academic achievement suggests that a clear relationship exists among locus of control, self-efficacy, how students attribute their success and failure, and academic performance. The field of attribution theory as it relates to academic performance continues to evolve as it suggests ways in which students can better understand their explanations of success or failure and their relationship to success in college.

Some of the studies reviewed report that students tend to adopt attributions for success and failure in the early grades (Amit, 1988; Bassarear, 1986; Kloosterman, 1988, 1993). This is useful in understanding the characteristics of students beginning their college education as were the students in this study. From the research on attribution retraining it is evident that understanding how students explain their success and failure serves as yet another tool that can be used to assist students who need to improve their academic achievement. Research on attribution retraining also supports the need to understand how students attribute their success and failure.

This review of the literature suggests that there is a rich historical research base for the development of attribution theory. The theory is well organized and attempts to account for the explanation of behavior. The research illustrates that different attribution patterns have been identified for successful and unsuccessful students. Successful students attribute their performance to internal, stable, controllable causes. Unsuccessful students attribute their performance to internal, unstable, controllable causes. The 
research demonstrates a distinct difference between academically successful and unsuccessful students in regard to their attribution patterns.

As evidenced by this review of the literature, the vast majority of the studies have been conducted in disciplines other than mathematics with samples showing little diversity. This study builds on previous research on attributions and academic achievement and provides more information on the relationship between success in College Algebra and attributions. It also contributes to the research by providing more information about attributions and their relationships to success and failure among a diverse student sample enrolled in a high-risk College Algebra course. 


\section{CHAPTER III}

\section{METHODS}

The literature makes a good case for the connection between attribution theory and student learning outcomes. Low success rates in College Algebra create a need to find new strategies that will lead to improved student performance. The literature focused on attributions and their relationship to achievement, mathematics achievement, self-efficacy, and locus of control but not specifically to the factors which can be related to the success and failure in College Algebra. Therefore, the purpose of this study was to examine the difference in the attributions passing and failing students gave for their performance on a College Algebra test. Four hundred and ten students enrolled in the same College Algebra course were asked to react to their academic performance based on their self-reported grade on an in-class test. This chapter provides a description of the population and sample and an explanation of the methods employed, including research design, instrumentation, data collection, processing, and analysis.

\section{Research Design}

The research design for this study was a self-report survey in which students expressed their attributions for success or failure on an in-class College Algebra test. The survey was constructed to allow students to quantify their self-reported attributions along four dimensions (i.e., locus of causality, stability, personal controllability, and external controllability). Comparisons for these attributions were made between the group of students who passed the test and the group of students who failed the test. The dependent variables were the four dimensions measured by the survey instrument. Performance on the test served as the independent variable. 
The researcher submitted all pertinent study information and documentation to Miami Dade College's Office of Institutional Research. Permission was granted to proceed with the study. This information, along with the required application and documentation, was then submitted to Florida International University's Institutional Review Board for human subjects approval. The study was approved as "exempt" as all conditions were met in that category. The cover letter for the survey instrument was stamped and dated so that the survey could be duplicated as necessary.

\section{Population and Sample}

The population in this study was freshman and sophomore students enrolled in a mathematics course, College Algebra (MAC 1105) at Miami Dade College during the Spring 2004 term. This course is considered a high-risk course due to its low success rates. Miami Dade College defines high risk courses as those courses with a semester enrollment of at least 300 students collegewide and pass rates below $60 \%$. During the period the study was conducted it was reported that $52 \%$ of students enrolled in this course did not receive a passing grade (Miami Dade College, 2004).

MAC 1105 is a three-credit course that partially fulfills a six-credit general education requirement in mathematics. During the Spring 2004 semester there were 136 sections of MAC 1105 with a total of 4,695 students (Miami Dade College, 2004). From this population, 24 sections were randomly selected generating a sample size of 410 respondents yielding 407 usable surveys. A cluster sample using a random number generator was conducted by the Office of Institutional Research at Miami Dade College. Individual class sections of MAC 1105 were used as the unit of selection for the random 
sample. This included the surveys of the 40 students who participated in the pilot. Three surveys were excluded from the data analysis because they were blank. The 410 respondents were classified into two separate groups based on their performance on the test. As a result of a discussion with mathematics faculty participating in this study, a grade of $75 \%$ was operationally defined as passing. Students who received a grade of $75 \%$ or higher were classified into the Passing Group $(n=237)$. All others were classified into the Failing Group $(n=173)$. The sample group was further divided in order to define the group of students self-reporting test grades in the top one-third and bottom one-third. The top one-third group was defined as students self-reporting a test grade in the range of $67-100(n=126)$. The bottom one-third was defined as students self-reporting a test grade in the range of 0-33 $(n=161)$. Table 2 presents demographic information for the population of MAC 1105, College Algebra during the Spring Term, 2004. The sample was drawn from this population. It presents the breakdown by gender, ethnicity, age, and native language. 
Table 2

MAC 1105 Student Profile for Spring Term $2004(N=4,691)$

Characteristics

Number

Percent

Gender

Ethnicity

$\begin{array}{lll}\text { Male } & 1,878 & 40.0 \\ \text { Female } & 2,813 & 60.0\end{array}$

White Non-Hispanic

479

10.2

Black Non-Hispanic

956

20.4

Hispanic

3,150

67.1

Other

62

1.3

Unknown

44

0.9

Age

$\begin{array}{lrr}18 \text { or younger } & 338 & 7.2 \\ 19-20 & 1,551 & 33.1 \\ 21-24 & 1,443 & 30.8 \\ 25-30 & 680 & 14.5 \\ 31-35 & 274 & 5.8 \\ 36 \text { or older } & 405 & 8.6\end{array}$

Native Language

$\begin{array}{lrr}\text { English } & 2,421 & 51.6 \\ \text { Spanish } & 1,953 & 41.6 \\ \text { French/Creole } & 217 & 4.6 \\ & & \\ \text { Other } & 100 & 2.1\end{array}$

Note. Miami Dade College, Office of Institutional Research. 2004.

Instrumentation

The survey instrument used to measure attributions was the Revised Causal

Dimension Scale II (CDSII) (McAuley, Duncan, \& Russell, 1992). The CDSII is designed to assess the perceptions of causal attributions for events in terms of the underlying dimensions identified by Weiner (1979) in his model of attribution processes. Weiner's categories and the corresponding items on the CDSII are illustrated in Table 3. 
Table 3

Relationship Between CDSII Items and Weiner's Attribution Categories

CDSII Items $\quad$ Weiner's Categories

Internal Locus of Causality

External Locus of Causality

Invariant Stability

Changeable Stability

Personal Controllability

External Controllability
Ability, Effort

Task Difficulty, Luck

Task Difficulty

Effort, Luck

Effort

Task Difficulty, Luck

Note. (McAuley, Duncan, \& Russell, 1992).

The instrument rates the causal explanations for events on 12 items, which yield measures for locus of causality, stability, personal controllability, and external controllability. Scores on the CDSII have been found to predict a variety of affective and cognitive variables in both achievement and non-achievement settings. Using Cronbach's alpha, the authors reported internal consistency of coefficients of .67 for locus of causality, .67 for stability, .79 for personal controllability, and .92 for external controllability. These values are within the acceptable range for instruments of this kind (Nunnally, 1978). In this study, the reliability and validity of the questionnaire were also evaluated. Reliability was measured by the computation of Cronbach's alpha coefficients. Validity was evaluated with a principal component factor analysis conducted using both an orthogonal rotation and an oblique rotation. The rotations were 
conducted to achieve simpler and more interpretable factorial structures. The oblique analysis was conducted in addition to the more typical orthogonal analysis because some of the variables in the survey were reported in the literature as correlated (Cantrell, 2001; Russell, 1982; Winn, 1995). The results of these procedures are reported in Chapter IV. The questionnaire begins with a cover letter giving the title of the research, an explanation of the purpose of the study, disclosures related to consent and anonymity, directions for retuming the questionnaire to the researcher, and contact information (See Appendix A). The CDSII consists of 12 bi-polar items, with three of the items assessing each of the four causal dimensions (i.e., locus of causality, stability, personal controllability, and external controllability) (See Appendix B). Respondents were first asked to self-report their actual grade on an in-class test. They were then asked to describe in an open-ended statement using their own words the cause of their performance on the test. After the respondents stated an attribution for their performance, they rated that cause on the CDSII using a 9-point Likert scale. Scores for the locus of causality, stability, personal controllability, and external controllability were derived by adding the ratings for each of the four semantic differential items representing that dimension. Means were calculated for each of the four dimensions. The causal attributions measured by the CDSII with their corresponding item numbers and descriptors are presented in Table 4. 
Table 4

Causal Attributions and Their Corresponding Items on the CDSII

Causal Attribution Item Description of Anchors

Locus of causality

1

6

9

Stability

$\begin{array}{ll} & 7 \\ & 11 \\ & \\ & 2 \\ 4 & 4 \\ & 10\end{array}$

External controllability $\quad 5$

8

12
Aspect of yourself/Aspect of situation

Inside of you/Outside of you

About you/About others

Permanent/Temporary

Stable/Variable

Unchangeable/Changeable

Manageable by you/ Not manageable by you

You can regulate/You cannot regulate

You have power/You have no power

Others have control/Others have no control

The power of others/Not the power of others

Others regulate/Others cannot regulate

Pilot of the Instrument

A pilot was conducted with 40 College Algebra students enrolled in one section of MAC 1105, College Algebra at Miami Dade College during the Summer 2003 Term. Students took their first in-class exam. The following week their instructor returned the graded exam, and students were given the cover letter (see Appendix A) and the CDSII (see Appendix B). All instructions on how to complete the questionnaire were provided 
by the researcher. Students were debriefed after they had completed the survey. They indicated the instructions were clear and appropriate and they were able to rate themselves without difficulty. These 40 surveys were considered to be usable as part of the sample for this study and were included in the analyses.

\section{Procedure}

This research study was conducted during the Spring 2004 semester. Twenty-four course sections of MAC 1105 were randomly selected by the Office of Institutional Research at Miami Dade College. Students were given the survey to complete during the class session when the first grade of the semester was returned by the faculty member. This was approximately the fifth week of a sixteen week term. The timing of the study was coordinated with the faculty involved so that it would coincide with students in all sections selected for this study reacting to an actual grade on the first test of the semester. Self-reported grades were not verified against actual grades. All of the faculty members participating in this study agreed to give the first test on the fourth week of the term as requested by the researcher. All of the students were instructed to complete the CDSII during class time. They were instructed to first report their actual grade as indicated on their test paper and then respond to an open-ended question that required them to state in their own words a reason for that performance. After the students had stated an attribution for the performance, they were directed to rate that cause on the CDSII. This rating was completed using a 9-point Likert scale along the dimensions of locus of causality, stability, personal controllability, and external controllability. All completed surveys were collected at the end of each class session by the instructor and delivered to the researcher. 


\section{Data Processing and Analysis}

The data collected were stored in a computerized file, transformed, and analyzed as described below.

\section{Raw Data File}

The responses contained in the 407 usable surveys, including the 40 surveys from the pilot were transferred to a computerized data file using SPSS, the software package utilized for statistical analyses in this study. The raw data file contained 17 columns, the first column was used for the respondent number, the second column was used for the grade, and the third column was used for the code assigned to the open-ended statements. The remaining 14 columns were used for the 12 responses to the 12 items on the CDSII and the coding of pass/fail and top and bottom one-third of the test scores. The data were entered using the same numerical codes associated with each possible response in the survey. Missing responses were codified using the code of 0 .

\section{Data Transformations}

The data needed four transformations before the analyses could be conducted. The first transformation consisted of the creation of a variable in which the respondents were classified as passing or failing. A second set of transformations was the computation of four separate scores for locus of causality, stability, personal controllability, and external controllability dimensions. The score for each of the four dimensions was computed by averaging the scores on the three questions for each of those dimensions. The locus of causality score was computed by averaging the scores on items 1,6 , and 9 . The stability score was computed by averaging the scores on items 3 , 7 , and 11 . The personal controllability score was computed by averaging the scores on 2 , 
4 , and 10 . The external controllability score was computed by averaging the scores on 5 , 8, and 12. A third set of transformations was completed in order to code the open-ended attribution statements made by the students. The statements were analyzed, classified, and coded by the researcher using the following categories: (a) ability, (b) effort, (c) task difficulty, and (d) luck. A fourth set of transformations was conducted in order to code the test scores according to their ranking within the top one-third or bottom one-third of the sample.

Data Analysis

Once the data file was completed with the necessary transformations, several statistical analyses were performed to evaluate the reliability and factorial structure of the survey instrument and answer the research questions.

Evaluation of the CDSII. The internal consistency of the items in the four dimensions (i.e., locus of causality, stability, personal controllability, and external controllability) included in the CDSII was measured by the computation of Cronbach's alpha coefficients. The factorial structure of the survey was evaluated with a principal component factor analysis which was applied to the 12 items of the survey. Orthogonal and oblique rotation procedures were conducted. The results of these analyses were reported in Chapter IV.

Comparisons of attributions between passing and failing students. The following hypotheses guided these analyses:

1. Students who pass the College Algebra test will attribute their performance on the test to internal causes. 
2. Students who pass a College Algebra test will attribute their performance on the test to stable causes.

3. Students who pass a College Algebra test will attribute their performance on the test to causes under their personal control.

4. Students who pass a College Algebra test will attribute their performance on the test to causes which others cannot control.

5. Students who pass a College Algebra test will give open-ended attribution statements of ability and effort to explain their performance on the test.

These hypotheses were tested by applying a One-Way ANOVA model to the four dimensions of causal attributions (i.e., locus of causality, stability, personal controllability, and external controllability) in the group of students with a passing grade and the group of students with a failing grade. The results of the ANOVA analyses were examined to determine whether a statistical difference existed between the causal attributions given by students who passed the test and students who failed the test A significance level of $p=.05$ was used in this study.

An analysis of attributions made by students scoring in the top one-third versus the bottom one-third on the College Algebra test was conducted in order to compare their rank with the causal attributions. This additional analysis was conducted in an effort to meet assumptions more closely. A Pearson chi-square was used to test for differences.

Analysis of the Open-Ended Attributions. A third measure of the causal attributions was conducted in order to determine whether a statistical difference existed between the way passing and failing students explained the cause of their performance when asked to do so in their own words. The researcher tabulated, transcribed, and 
classified the open-ended statements according to themes found within the statements. These themes were then further classified along the factors related to attributions (Weiner, 1972; Weiner \& Kukla, 1970) as presented in Table 5. A Pearson chi square test for differences in proportions was conducted to calculate the differences between the passing and failing students. It was determined that a chi square analysis was most appropriate for the following reasons: (a) the sample for this study was randomly drawn from the population; (b) the data were collected in raw frequencies, not percentages; (c) the measured variables were independent as students were either in the passing group or the failing group and not in both; (d) the minimum frequency for any of the observations was not below 5; and (e) this procedure was the appropriate one to use for designs of uneven group sizes.

Table 5

Coding of Attributions Among Factors

Scales of Attributions Factors

Locus of causality

Internal

External
Ability

Task Difficulty
Effort

Luck

Stability

$\begin{array}{lll}\text { Stable } & \text { Ability } & \text { Task Difficulty } \\ \text { Unstable } & \text { Effort } & \text { Luck }\end{array}$

Personal controllability Effort

External controllability Task Difficulty Luck 


\section{Summary}

In order to measure the causal attributions students give for their academic performance, the CDSII was selected as the survey instrument for this study. The CDSII measures causal attributions along the dimensions of locus of causality, stability, personal controllability, and external controllability.

The CDSII was administered to 410 college freshman and sophomore students enrolled in College Algebra (MAC 1105). Students were instructed to complete the survey instrument upon receiving their grade on the first test given in class.

The data collected were stored in an SPSS file and subjected to transformations necessary for the statistical analyses. Cronbach's alpha coefficients were computed to evaluate the reliability of the scales measuring locus of causality, stability, personal controllability, and external controllability. The factorial validity of the survey instrument was also examined.

The hypotheses regarding the difference between the causal attributions given by students who pass and students who fail a College Algebra test were tested by developing ANOVA models for each of the dimensions of causal attributions. A Pearson chi square test was conducted in order to determine any differences between the attributions of students scoring in the top one-third and the bottom one-third on the College Algebra test. An analysis of the open-ended attribution statements given by passing and failing students was also conducted using a Pearson chi square test. The findings are reported in Chapter IV. 


\section{CHAPTER IV}

\section{FINDINGS}

The purpose of this study was to examine the difference in the attributions given for success or failure between students who pass and students who fail a College Algebra test. The findings of this study are reported in this chapter. Results of reliability and principal component analyses of the survey instrument and One-Way ANOVA and Pearson chi square calculations to determine the significant differences in attributions given for performance between passing and failing students enrolled in College Algebra are reported.

\section{Reliability Analysis of the CDSII}

In order to determine the internal consistency of the four dimensions as measured by the CDSII (i.e., locus of causality, stability, personal controllability, and external controllability), alpha coefficients were calculated (Cronbach, 1951). The average reliability coefficients for locus of causality, stability, personal controllability, and external controllability were between .67 and .83 . These values are considered acceptable for instruments of this type (Nunnally, 1978). The reliability coefficients for the four scales are shown in Table 6 . These findings are consistent with the results reported by McAuley, Duncan, and Russell (1992). 
Table 6

Reliability of the Four Causal Attribution Dimensions of the CDSII

Causal Attribution Dimension

$\alpha$

Locus of causality

.67

394

Stability

.68

397

Personal controllability

.83

398

External controllability

.72

398

Factorial Structure of the Survey

The principal component analysis conducted yielded four significant factors:

factor 1 accounted for $29 \%$ of the variance; factor 2 accounted for $21 \%$ of the variance; factor 3 accounted for $10 \%$ of the variance; and factor 4 accounted for $7 \%$ of the variance. The four factors accounted for $68 \%$ of the variance. An orthogonal rotation procedure was applied to the 12 questions related to the causal attribution dimensions measured by the survey instrument (i.e., three questions measuring locus of causality, three questions measuring stability, three questions measuring personal controllability, and three questions measuring external controllability). A Varimax rotation was performed in order to obtain a simpler structure of factors that would be easier to interpret. As a result of this analysis, four factors were obtained. The first one represented the locus of causality dimension with the three questions related to this dimension loading into this factor with correlation coefficients ranging from .48 to .75 . The three stability questions loaded into the second factor with correlation coefficients 
ranging from .59 to .83 . The three questions related to personal controllability loaded into the third factor with correlation coefficients ranging from .81 to .84 . The three questions related to external controllability loaded into the fourth factor with correlation coefficients ranging from .74 to .83 . The results of this factor analysis are presented in Table 7.

Table 7

Factors and Loadings for the Scores of Causal Attributions using Orthogonal Rotation

Causal Attributions

Factor 1

Factor 2

Factor 3

Factor 4

Aspect of self/situation

.480

.481

.232

.000

Inside/outside self

.745

.172

.298

$-.008$

About self/others

.730

.003

.338

$-.007$

Permanent/temporary

.113

.829

.000

.114

Stable/variable

.328

.588

.167

.109

Unchangeable/changeable

$-.009$

.804

$-.107$

.157

Self manage/not

.272

.004

.807

$-.005$

Self regulate/not

.139

.001

.843

$-.004$

Self power/not

.287

.004

.816

$-.007$

Others control/not

$-.241$

.232

.128

.740

Power of others/not

$-.175$

.236

$-.139$

.764

Others regulate/not

.262

$-.006$

$-.149$

.830 
In situations where the correlations between the underlying constructs are not assumed to be zero, an oblique rotation procedure may yield simpler and more interpretable factor patterns (University of Texas, 1995). Since the literature describes that some of the variables included in the questionnaire are correlated, an oblique factor analysis was also conducted. For example, personal and external controllability were found to be correlated in other studies (Russell, 1982; Winn, 1995).

This oblique rotation procedure also yielded four factors. The three questions measuring locus of causality loaded on the first factor and showed correlation coefficients with the underlying factor from .53 to .80 . The three questions measuring stability loaded on the second factor and showed correlation coefficients with the underlying factor from .64 to .84 . The three questions measuring personal controllability loaded on the third factor and showed correlation coefficients with the underlying factor of .85 to .86. The three questions measuring external controllability loaded on the fourth factor showed correlation coefficients with the underlying factor of .75 to .82 . Table 8 summarizes the results of the oblique rotation procedure.

The results of the two rotation procedures provided evidence of factorial validity for the questions measuring locus of causality, stability, personal controllability, and external controllability. Although the orthogonal rotation procedure provided a better fit than the oblique rotation procedure, the two procedures presented the highest loadings on the same questions and the same three questions are retained in the factor scores. The questions loaded into four factors in a manner consistent with the validity reported by McAuley, Duncan, and Russell (1992). One weakness observed in both rotation 
procedures for the locus of causality dimension was that one of the three questions not only loaded into the locus of causality factor, but also into the stability factor.

Table 8

Factors and Loadings for the Scores of Causal Attributions using Oblique Rotation

Causal Attributions

Factor 1

Factor 2

Factor 3

Factor 4

Aspect of self/situation

.528

.540

.367

.031

Inside/outside self

.796

.259

.473

.096

About self/others

.785

.121

.499

$-.104$

Permanent/temporary

.128

.843

.080

.200

Stable/variable

.361

.639

.271

.155

Unchangeable/changeable

.099

.795

.077

.250

Self manage/not

.422

.107

.850

$-.106$

Self regulate/not

.297

.062

.852

.094

Self power/not

.440

.103

.863

$-.125$

Others control/not

$-.262$

.303

.055

.754

Power of others/not

$-.248$

.304

$-.190$

.795

Others regulate/not

.163

.072

$-.124$

.823

Results of Hypotheses

The purpose of this study was to examine the difference in the attributions given for performance between students who passed and students who failed a College Algebra test. Five hypotheses guided this study: 
1. Students who pass the College Algebra test will attribute their performance on the test to internal causes.

2. Students who pass a College Algebra test will attribute their performance on the test to stable causes.

3. Students who pass a College Algebra test will attribute their performance on the test to causes under their personal control.

4. Students who pass a College Algebra test will attribute their performance on the test to causes which others cannot control.

5. Students who pass a College Algebra test will give open-ended attribution statements of ability and effort to explain their performance on the test.

To examine these differences for Hypotheses 1 through 4, a One-Way Analysis of Variance (ANOVA) was conducted for each of the four dimensions comparing the groups of passing and failing students. A Pearson chi square procedure was performed and analyzed for the statistical differences between the groups of students scoring in the top one-third and bottom one-third on the College Algebra test. The range of selfreported scores from actual test grades ranged from 0 to 100. For Hypothesis 5, a Pearson chi square analysis was performed in order to determine a difference in the attribution statements made between students in the passing and failing groups.

\section{Analyses of CDSII Scales Across Groups}

A One-Way ANOVA was conducted to compare means in each of the four dimensions of attributions (i.e., locus of causality, stability, personal controllability, and external controllability) by performance on an in-class College Algebra test. The data analysis involved a comparison of the mean rating for each dimension of attribution as 
measured by the CDSII for the passing $(n=235)$ and failing $(n=172)$ groups.

Means and standard deviations for the locus of causality dimension in the analysis for significant differences between the group of students with passing grades and the group of students with failing grades are presented in Table 9. Students in the passing group showed a significantly higher mean at $p=.05$, indicating that for the locus of causality dimension the group of students with passing grades tended to attribute their performance to internal factors $(M=6.76, S D=1.56)$ more than the students with failing grades $(M=5.94, S D=1.62)$. It is concluded that students in the passing group rated internality more highly as an attribution for their performance than students in the failing group. As a result, this supported the assertion of Hypothesis 1 that students in the passing group attributed their performance on the College Algebra test to internal causes. Table 9

Means and Standard Deviations for Locus of Causality

\begin{tabular}{lccc} 
Ratings & $n$ & $M$ & $S D$ \\
\hline Pass & 235 & 6.76 & 1.56 \\
Fail & 172 & 5.94 & 1.62
\end{tabular}

Total 407

Means and standard deviations for the stability dimension as analyzed for the significant differences between the groups of students with passing grades and the group of students with failing grades are presented in Table 10. The findings indicate that for the stability dimension, students in the passing group showed a significantly higher mean 
at $p=.05$, indicating that they tended to attribute their performance to stable causes $(M=5.15, S D=2.09)$ more than the group of students with failing grades $(M=4.15, S D=1.62)$. These findings indicate that students in the passing group rated stability higher than the students in the failing group. As a result, the assertion of Hypothesis 2 that passing students attribute their performance to stable causes is supported.

Table 10

Means and Standard Deviations for Stability

\begin{tabular}{lccc} 
Ratings & $n$ & $M$ & $S D$ \\
\hline Pass & 235 & 5.15 & 2.09 \\
Fail & 172 & 4.15 & 1.62 \\
Total & 407 & & \\
\hline
\end{tabular}

Means and standard deviations for the personal controllability dimension as analyzed for significant differences between the group of students with passing grades and the group with failing grades are presented in Table 11. The findings indicate that for this dimension students with passing grades had a significantly higher mean at $p=.05$, indicating that they attributed their performance to causes within their control $(M=7.30, S D=1.50)$ and that students with failing grades also attributed their performance to causes outside of their control $(M=6.26, S D=1.76)$. As a result, the assertion of Hypothesis 3 that students within the passing group attribute their performance on a test to causes under their personal control is supported. 
Table 11

Means and Standard Deviations for Personal Controllability

Ratings

$n$

$M$

$S D$

\begin{tabular}{lccc}
\hline Pass & 235 & 7.30 & 1.50 \\
Fail & 172 & 6.26 & 1.76 \\
Total & 407 & & \\
\hline
\end{tabular}

Means and standard deviations for the external controllability dimension analyzed for significant differences between the groups of students with passing grades and failing grades are presented in Table 12. The findings indicate that for this dimension, both groups attributed the cause of their performance to causes outside of their control (Mpassing $=4.18, S D=2.01 ; M_{\text {failing }}=4.07, S D=1.91$ ). These results failed to support Hypothesis 4 that students who pass a College Algebra test will attribute their performance on the test to causes which others cannot control.

Table 12

Means and Standard Deviations for External Controllability

Ratings

$n$

M

$S D$

Pass

235

4.18

2.01

Fail

172

4.07

1.91

Total

407 
A summary of all means computed for the groups of passing and failing students is presented in Table 13.

Table 13

Summary of Means Across Pass/Fail Groups

CDSII Items

Passing Group

Failing Group

Locus of Causality

6.76

5.94

Stability

5.15

4.15

Personal Controllability

7.30

6.26

External Controllability

4.18

4.07

A One-Way ANOVA for each of the four dimensions measured by the CDSII yielded significant differences at $p=.05$ among performance groups in three of the four dimensions (locus of causality, stability, and personal controllability).

The results for locus of causality dimension are presented in Table 14. These findings indicate a statistically significant difference between the passing and failing students in the locus of causality dimension at $F(1,406)=26.34, p<.0001$. 
Table 14

One-Way ANOVA Summary Table for Locus of Causality by Pass/Fail

Source

$d f$

SS

$M S$

F

Between Groups

1

66.447

66.447

$26.340^{*}$

Within Groups

406

1024.219

2.523

Total

407

1090.666

$* p<.0001$

The results for stability are presented in Table 15 . These findings indicated that there is a statically significant difference between the passing and failing students in the stability dimension at $F(1,405)=26.96, p<.0001$.

Table 15

One-Way ANOVA Summary Table for Stability by Pass/Fail

Source

$d f$

SS

MS

F

Between Groups

1

98.575

98.575

$26.967^{*}$

Within Groups

405

1480.466

3.655

Total

406

1579.041

${ }^{*} p<.0001$

The results for personal controllability are presented in Table 16. These findings indicated that there is a statistically significant difference between passing and failing students in the personal controllability dimension at $F(1,405)=40.92, p<.0001$. 
Table 16

One-Way ANOVA Summary Table for Personal Controllability by Pass/Fail

Source

$d f$

SS

MS

F

Between Groups

1

107.173

107.173

40.926*

Within Groups

405

1060.567

2.619

Total

406

1167.739

$* p<.0001$

The results for external controllability are presented in Table 17. These findings indicated no significant difference between the passing and failing students in the external controllability dimension.

Table 17

One-Way ANOVA Summary Table for External Controllability by Pass/Fail

Source

$d f$

SS

$M S$

$F$

Between Groups

1

1.086

1.086

.598

Within Groups

405

1578.891

3.898

Total

406

1579.977

Correlation Analysis Between Upper One-Third and Bottom One-Third and Attributions

In order to test the assumption that the most consistent or reliable attributions will occur at the extremes and that it is at the extremes that scores are likely to be interpreted or perceived as success or failure, an analysis of the group of students scoring in the 
upper one-third and students scoring in the bottom one-third on the College Algebra test was performed. Students determined to be in the top one-third of the group were those students self-reporting a grade of $67-100(n=126)$ on the College Algebra test.

Students determined to be in the bottom one-third of the group were those students selfreporting a grade of $0-33(n=161)$ on the College Algebra test. In order to determine whether there was a significant difference, a Pearson chi square test was computed for each the four dimensions measured by the CDS II along these two groups. For the locus of causality dimension, the results indicated a significant difference at $\chi^{2}(26, N=288)=$ $59.631, p=.0001$. When examining the data within the parameters of high internality (ratings of 8-9 on the CDSII), $67 \%$ of the students in the top one-third group gave locus of causality a rating of 8 or above. These findings support the assumption of Hypothesis 1 that students in the passing group attribute their performance on a College Algebra test to internal causes.

For the stability dimension, the results indicated a significant difference at $\chi^{2}(24, N=287)=70.736, p=.0001$. When examining the data within the parameters of high stability (ratings of $8-9$ on the CDSII), $83 \%$ of the students in the top one-third group gave stability a rating of 8 or above. These findings support the assumption of Hypothesis 2 that students in the passing group attribute their performance on a College Algebra test to stable causes.

For the personal controllability dimension, the results indicated a significant difference at $\chi^{2}(24, N=287)=70.513, p=.0001$. When examining the data within the parameters of high personal controllability (ratings of $8-9$ on the CDSII), $52 \%$ of the students in the top one third group gave personal controllability a rating of 8 or above. 
These findings support the assumption of Hypothesis 3 that students in the passing group attribute their performance on a College Algebra test to causes for which they have personal control.

When testing for the external controllability dimension, the results did not indicate a significant difference between the students in the top one-third group and the students in the bottom one-third group. The analysis reported that $73 \%$ of the students in both groups rated external controllability at 5 or below on the CDSII scale. These results did not support the assumption of Hypothesis 4 that students in the passing group attribute their performance on a College Algebra test to causes that are not controlled by external factors.

\section{Findings of the Tabulation of Open-Ended Causal Attributions}

Once the open-ended causal attribution statements were classified and coded, a Pearson chi square test for differences in proportions was calculated to test for significant differences in the types of attributions made by students who passed and students who failed. The analyses were conducted to test each attribution separately. There was a significant difference between the types of attribution statements made by students who passed and students who failed in the attribution categories of effort and task difficulty. This finding partially supported Hypothesis 5 that students in the passing group give open-ended statements relating to effort as the cause of their performance on a College Algebra test. The results of these analyses did not support the assumption of Hypothesis 5 that students in the passing group will give open-ended attribution statements regarding their performance on a College Algebra test to causes relating to ability. 
A summary of the analyses conducted within each of the four classifications given to the open-ended attribution statements are presented in Table 18.

Table 18

Pass/Fail Groups and Open-Ended Attribution Statements

Attribution Classifications

$n$

$d f$

$F$

$p$

\begin{tabular}{lrrrr}
\hline Ability & 79 & 1 & .178 & .673 \\
Effort & 194 & 1 & 5.641 & .018 \\
Task Difficulty & 58 & 1 & 7.463 & .006 \\
Luck & 9 & 1 & .673 & .412 \\
\hline
\end{tabular}

The open-ended attribution statements were analyzed further in terms of their distribution among both groups. The attribution statement category most commonly used by both groups was effort. Students in the passing group gave effort statements such as "because I studied" and "I prepared for the test." Students in the failing group gave effort statements such as "I did not study enough" and "I could have studied more." The next category most often used by the passing group was ability. Students in the passing group gave statements such as "I understood the material" and "because I knew the concepts." The next two categories most commonly used by the failing group were ability and task difficulty. Statements such as "lack of understanding" and "I am not a good math student" fell within the ability category, and statements such as "the test was too hard" and "the test was harder than I expected" fell within the task difficulty category. The distribution of the open-ended statements is presented in Table 19. 
Table 19

Attributions Frequency Distribution $(n=410)$

Attribution

Pass

Fail

Ability

$19.6 \%$

$18.8 \%$

Effort

$53.1 \%$

$40.3 \%$

Task Difficulty

$10.3 \%$

$18.8 \%$

Luck

$1.8 \%$

$2.7 \%$

Other Attribution

$5.4 \%$

$4.8 \%$

No Attribution

$9.8 \%$

$14.5 \%$

\section{Summary}

The factorial validity and reliability of the CDSII, the difference between the passing and failing groups and their attributions for success or failure, and a frequency distribution of the classified and coded open-ended causal attribution statements were presented. A principal component factor analysis of the CDSII yielded four factors. The three items measuring locus of causality loaded on the first factor, the three items measuring stability loaded on the second factor, the three items measuring personal controllability loaded on the third factor, and the three items measuring external controllability loaded on the fourth factor.

Presented in this chapter are the findings of the study that supported or failed to support the five hypotheses guiding the study: 
1. Students who pass the College Algebra test will attribute their performance on the test to internal causes. A statistically significant difference was found in the locus of causality dimension of students who passed and students who failed a College Algebra test. The findings indicated that students in the passing group attributed their performance on the College Algebra test to internal causes.

2. Students who pass the College Algebra test will attribute their performance on the test to stable causes. A statistically significant difference was found in the stability dimension of students who passed and students who failed a College Algebra test. The findings indicated that students in the passing group attributed their performance on the College Algebra test to stable causes.

3. Students who pass the College Algebra test will attribute their performance on the test to causes for which they have personal control. A statistically significant difference was found in the personal controllability dimension of students who passed and students who failed a College Algebra test. The findings indicated that students in the passing group attributed their performance on the College Algebra test to causes for which they have personal control.

4. Students who pass a College Algebra test will attribute their performance on the test to causes which others cannot control. There was no significant difference found in the external controllability dimension of students who passed and students who failed a College Algebra test. The findings indicated that students in the passing and failing groups attributed their performance on the College Algebra test to external control causes. 
5. Students in the passing group will give attribution statements of ability and effort to explain their performance on the College Algebra test. A statistically significant difference was found in the open-ended attributions statements students gave for their performance between the pass and fail groups in the categories of effort and task difficulty. The findings indicated that students in the passing group most often gave attribution statements to explain their performance on the College Algebra Test in the categories of ability and effort.

The differences between the passing and failing groups and the attributions they gave for their performance along the four dimensions (i.e., locus of causality, stability, personal controllability, and external controllability) were examined by applying a OneWay ANOVA to each of the four dimensions. The results for locus of causality, stability, and personal controllability were statistically significant at $p<.0001$. There was no significance found in the analysis for external controllability.

A Pearson chi square test was conducted to determine statistical differences between the students scoring in the top one-third and students scoring in the bottom onethird on the College Algebra test. Statistical significance was found in the locus of causality, stability, and personal controllability dimensions. No statistical significance was found in the external controllability dimension.

A frequency distribution was conducted for the open-ended causal attribution statements given by the students in both groups. This analysis reflected that there was a difference in the type of attribution statements students gave between the passing and failing groups. A Pearson chi square test was also performed, and the results indicated a 
statistically significant difference in the type of attribution statements made by students who passed and students who failed the College Algebra test.

The findings of this study were presented in this chapter. Chapter V presents a summary of the study, a discussion of the findings, conclusions based on the findings, limitations of the study, recommendations for practice, and recommendations for further research. 


\section{CHAPTER V \\ DISCUSSION}

A summary of the study, discussion of the findings, and a presentation of its conclusions, implications, limitations, and recommendations are found in this chapter.

\section{Summary of the Study}

Success in mathematics has been identified as a predictor of baccalaureate degree completion. Within the coursework in the college mathematics curriculum, College Algebra has been determined to be a "high risk" course due to its low success rate. This has made College Algebra an obstacle to program and degree completion for many students.

The work of Weiner $(1979,1982,1986)$ on attribution theory provided the theoretical framework for this study. Weiner's identification of the causal dimensions: locus of causality, stability, and controllability served as the foundation for the Causal Dimension Scale II (CDSII) (McAuley, Duncan, \& Russell, 1992). The CDSII was used as the survey instrument for this study.

Literature in the field of attribution theory suggests a relationship between the way students explain the causes of their academic performance and academic achievement. Research has reported that attributions can influence how individuals react to success and failure on achievement-type tasks. It has also been reported that attribution retraining does have an effect on academic performance. This could be of great significance in efforts toward the improvement of success rates in College Algebra. The research illustrates that different attribution patterns have been identified for successful and unsuccessful students. Successful students attribute their performance to 
internal, stable, and controllable causes. Unsuccessful students attribute their performance to internal, unstable, and controllable causes. The research demonstrates a distinct difference between academically successful and unsuccessful students in regard to their attribution patterns. As evidenced by the literature review conducted for this study, the vast majority of research has been conducted in disciplines other than mathematics with samples usually showing little diversity. This study builds on previous research on attributions and academic achievement and provides to the information on the relationship between success in College Algebra and attributions.

The purpose of this study was reflected in five hypotheses:

1. Students who pass a College Algebra test will attribute their performance on the test to internal causes.

2. Students who pass a College Algebra test will attribute their performance on the test to stable causes.

3. Students who pass a College Algebra test will attribute their performance on the test to causes within their personal control.

4. Students who pass a College Algebra test will attribute their performance on the test to causes which others do not control.

5. Students who pass a College Algebra test will give open-ended attribution statements of ability and effort to explain their performance on the test.

The CDSII (McAuley, Duncan, and Russell, 1992) was used to measure the causal attributions that College Algebra students gave when asked to react to their performance on an in-class College Algebra test. Although the authors of the CDSII reported adequate validity and reliability, principal component and reliability analyses 
were performed for the purposes of this study. The CDSII is composed of 12 items which require a rating on a Likert scale of 1-9. The survey instrument was designed to measure causal attributions along the dimensions of locus of causality, stability, personal controllability, and external controllability. Four separate One-Way ANOVA calculations were conducted in order to determine a statistical difference between the groups of passing and failing students in relation to the attributions they gave for their performance. A Pearson chi square procedure was also conducted in order to calculate significant differences between students self-reporting test scores in the top one-third (67-100) and bottom one-third (0-33) and their attributions. A frequency distribution of the open-ended causal attributions students gave for their performance on an in-class College Algebra test was conducted to analyze for any differences among the two groups. The two groups were compared by using a Pearson chi square procedure.

\section{Discussion of Findings}

The findings presented in Chapter IV are discussed below in relation to the reviewed literature. This section also provides a more comprehensive discussion of the assertions made by the hypotheses which guided this study.

Reliability Analysis of the CDSII

An analysis was conducted using Cronbach alpha coefficients. The average reliability coefficients for locus of causality, stability, personal controllability, and external controllability were between .67 and .83 . These results were consistent with the findings of McAuley, Duncan \& Russell (1992), and they were within the acceptable range according to Nunnally (1978). The results indicated that, as with the analysis conducted by the authors of the CDSII, the instrument was found to have internal 
consistency. This proved to be an important calculation since it provided the study with additional information regarding the reliability of the CDSII in measuring the four causal dimension scales.

\section{Factorial Structure of the Survey}

The results of a principal component factor analysis using orthogonal and oblique rotation procedures was applied to the 12 questions of the CDSII. It provided evidence of factorial validity for the dimensions measuring locus of causality, stability, personal controllability and external controllability. The procedures yielded four factors and these were the same factors found in the literature (McAuley, Duncan, \& Russell, 1992).

These four factors were: (a) locus of causality, (b) stability, (c) personal controllability, and (d) external controllability. The three questions measuring locus of causality, the three questions measuring stability, the three questions measuring personal controllability, and the three questions measuring external controllability all loaded on the same factors as reported by McAuley, Duncan, \& Russell (1992). This consistency with the validity reported by the authors of the CDSII also provided the study with assurance regarding the use of this instrument to test the research questions.

\section{Attributions of Passing and Failing Students}

Means for the locus of causality dimension as measured by the CDSII were calculated for passing and failing students. The means were calculated from the three questions measuring the locus of causality dimension. The mean score for the passing students was 6.76. Considering that the scale for locus of causality ranged from 9.00 (aspect of yourself, inside of you, about you) to 1.00 (aspect of the situation, outside of you, about others), the results indicated that the passing group attributed the cause of their 
performance in the direction of internality. These results are consistent with other studies which have found that successful mathematics students and successful students in other disciplines generally attribute their success to ability and effort, both internal factors (Amit, 1988; Bassarear, 1986; Cantrell, 2001; Bernstein, Stephan, \& Davis, 1979; Kovenkloughu \& Greenhaus, 1978; Weiner, 1986). Although the mean for the passing group $(M=6.76)$ was in the direction of internality, this result did not represent what is considered a high internal score for the locus of causality dimension a measured by the CDSII (McAuley, Duncan, \& Russell, 1992). Since students were classified as passing or failing based on their self-reported grades, it is possible that the operational definition used for passing did not coincide with the students' perception. College Algebra, within the context of the institution where the study was conducted, and the characteristics of the students in the sample could further explain the findings. College Algebra is considered a high-risk course with a passing rate of less than $60 \%$. Although it is the first college level mathematics course within the general education curriculum, it is also a course in which students enroll after successful completion of remedial or developmental mathematics courses or placement by initial assessment at the time they are admitted to the institution. This could mean that students who pass a test in this course may not view themselves as successful College Algebra students, but rather as students who are not successful in College Algebra and happen to pass a test. The fact that they attributed their performance on the test in the direction of internality may be explained by their inability to see themselves as having the ability to succeed in College Algebra and are explaining their success in terms of something outside of themselves. This can be an asset as suggested 
by Platt (1988) who reported that students who attribute their success to internal causes are more likely to expect future success.

The mean score for the failing students was 5.94. This indicated that failing students also attributed their performance in the direction of internality. Although the results reflected a statistical difference at $p<.0001$ between the means of the passing and failing students in the locus of causality dimension, this was not considered a meaningful difference. These results were consistent with other studies reported in the literature which indicated that unsuccessful students tended to attribute their performance to external factors (Amit, 1988; Bassarear, 1986; Bernstein, Stephan, \& Davis, 1979; Kovenkloughu \& Greenhaus, 1978; Weiner, 1986). These studies also maintained that when students attribute their failure to external causes such as task difficulty, they are able to maintain a positive image of themselves, as an external cause such as task difficulty is something that can be seen as outside their control and can in fact change in the future (Kloosterman, 1988). The results as they relate to the failing students in this study are consistent with the literature and may provide a favorable outlook for failing students.

Means were calculated for the stability dimension as measured by the CDSII. The means were calculated from the three questions measuring the stability dimension. The mean score for the passing students was 5.15 . Considering that the range for the stability dimension was from 9.00 (permanent, stable, unchangeable) to 1.00 (temporary, variable, changeable), the results indicated that passing students attributed their performance on the test in the direction of stability. These results were consistent with other studies which reported that students attribute their success to stable causes (Bernstein, Stephan, 
\& Davis, 1979; Cantrell, 2001; Weiner, 1986; Weiner \& Kukla, 1970). The results represented a weak directionality to stability. This may be attributed to the nature of the students enrolled in this particular College Algebra course. It is of interest to the researcher that students with passing grades on a test in this class tended to rate their success within the mid-point for the stability dimension. This could be an indicator of their lack of confidence in mathematics and/or their past academic history.

Students with failing grades on the test showed a mean score of 4.15 . This resulted in statistical significance at $p<.0001$. It also indicated that failing students attributed the cause of their performance in the direction of instability. This is inconsistent with other studies found in the literature which have reported that unsuccessful students explain their academic failure on causes that are stable, unchangeable, and permanent (Bernstein, Stephan, \& Davis, 1979; Weiner, 1986; Weiner $\&$ Kukla, 1970). Since attributions can affect the expectations of any future performance, it is encouraging that failing students in this study described their performance as unstable. This was suggested in the literature by the work of Wilson and Linville (1982) which reported that convincing students that their academic failure was temporary could prove to be of long-term benefit in their academic endeavors. These findings are also encouraging as reflected by the theoretical constructs of attribution presented by Weiner (1986) which showed that once individuals change their attributions for poor performance to unstable causes, they can raise their expectations about future performance. This can become a powerful strategy in a course such as College Algebra due with a low success rate and prominence in the curriculum. 
Means were calculated for the personal controllability dimension as measured by the CDSII for passing and failing students. The means were calculated from the three questions measuring personal controllability. The personal controllability dimension as measured by the CDSII produced a mean of 7.30 for the passing group. The range for the ratings were from 9.00 (manageable by you, you can regulate, you have power) to 1.00 (not manageable by you, you cannot regulate, you have no power). The results of the passing group reflect that passing students attribute their performance in the direction of personal controllability. The results of other studies on personal controllability and its relationship to academic achievement are consistent with the results of this study. They report that successful students attribute their success to causes for which they feel they have personal or internal control (Biggs, 1987; Cantrell, 2001; Weiner, et. al, 1972; Weiner \& Kukla, 1970). The results for this dimension reflected a high personal controllability factor (McAuley, Duncan, \& Russell, 1992) indicating that students who self-reported a passing grade on the College Algebra test attributed their performance to causes they personally managed or controlled.

Students in the failing group showed a mean score of 6.26. This reflected a statistical significance at $p<.0001$ between the passing and failing groups. This was not considered a meaningful difference when compared to the results of the students in the passing group, these students also attributed their performance on the test in the direction of personal controllability. These results are also consistent with the literature suggesting that both passing and failing students attribute performance to factors within their personal control (Winn, 1995). These results provide a positive outlook for students in the failing group who tended to attribute their performance to causes within their personal 
control as this could have further impact on future performance and contribute to increased achievement (Biggs, 1987).

The results of the external controllability dimension as measured by the CDSII indicated that both the passing group and the failing group attributed their performance in the direction of external controllability. No significant difference was found between the two groups. This finding was inconsistent with other studies which reported that successful students attribute their success to causes which they control (Biggs, 1987; Cantrell, 2001). Winn (1995) also found no significant difference in the external controllability dimension. These results could be indicative of a misunderstanding on the part of the students regarding the language used for these three questions on the CDSII. Evidence of this may be observed in the fact that students in the passing group rated personal controllability high, thus creating an inconsistency with the rating they gave to the external controllability dimension. Questions regarding the external controllability dimension as measured by the CDSII have also been reported in the literature (Cantrell, 2001; Russell, McAuley, \& Tarico, 1987).

The results of a Pearson chi square calculation reported significant differences between the groups of students with self-reported test scores in the top one-third and bottom one-third and their attributions for their performance. The locus of causality, stability, and personal controllability dimensions reported statistical significance at $p=.0001$. No significant difference was found for external controllability. These results are consistent with and provide support for the One-Way ANOVA analyses conducted for this study. 
An examination of the findings for the locus of causality dimension show that students in the top one-third group attributed their performance on the College Algebra test to internal causes more than students in the bottom one-third group. This is consistent with the literature which suggests that successful students attribute their performance to internal causes (Amit, 1988; Bassarear, 1986; Bernstein, Stephan, \& Davis, 1979; Cantrell, 2001; Kovenkloughu \& Greenhaus, 1978; Weiner, 1986). These findings also supported the assumptions of Hypothesis 1 that students in the passing group attribute their performance on the College Algebra test to internal causes.

The findings for the stability dimension indicated that students in the top one-third group attributed their performance to stable causes more than the students in the bottom one-third group. This was consistent with the results of other studies reporting that successful students attribute their performance to stable causes (Amit, 1988; Bassarear, 1986; Bernstein, Stephan, \& Davis, 1979; Cantrell, 2001; Kovenkloughu \& Greenhaus, 1978; Weiner, 1986). The findings supported the assumptions of Hypothesis 2 that passing students attribute their performance on a College Algebra test to stable causes.

The findings for the personal controllability dimension indicated that students in the top one-third groups attributed their performance to causes within their control more than the bottom one-third group. These results are the same as reported for other studies which suggest that successful students attribute their performance to causes within their control (Amit, 1988; Bassarear, 1986; Bernstein, Stephan, \& Davis, 1979; Cantrell, 2001; Kovenkloughu \& Greenhaus, 1978; Weiner, 1986). These findings support the assumptions of Hypothesis 3 that passing students attribute their performance on a College Algebra test to causes within their control. 
The findings for the external controllability dimension indicated that both the top one-third and the bottom one-third groups attributed their performance to causes for which others had control. This was consistent with the results reported by Cantrell (2001) and Winn (1995) suggesting that there was no difference in the dimension of external controllability between successful and unsuccessful students. As mentioned earlier, these results may be indicative of a semantic misunderstanding on the part of the students and what has been suggested by the literature as a problematic measure of this dimension (Cantrell, 2001; Russell, McAuley, \& Duncan, 1987; Winn, 1995). These results failed to support the assumptions of Hypothesis 4 that passing students attribute their performance on a College Algebra test to causes that are not controlled by external factors.

\section{Open-Ended Statements of Causal Attributions}

The open-ended statements passing and failing students made when asked to explain their performance on the test, were classified and coded in relation to their reference to: (a) ability, (b) effort, (c) task difficulty, and (d) luck. A Pearson chi square test reported a statistically significant difference between the type of attribution statements students in the passing group and students in the failing group gave for their performance, $\chi^{2}(5, N=410)=11.11, p<.05$.

An analysis of the frequency of the attribution statements reflects that, when asked to make open-ended statements regarding the cause of their performance, $72.7 \%$ of the students in the passing group gave statements which referred to their ability and effort. The highest attribution used was effort, followed by ability. This finding is consistent with other studies that report students who are successful tend to explain their 
academic success in terms of ability and effort (Bernstein, Stephan, \& Davis, 1979; Weiner et al., 1972; Weiner \& Kukla, 1970). As reported by Russell, McAuley, and Tarico (1987), when students in the passing group referred to effort, the statements generally involved a reference to how hard the student had prepared for the test. This is consistent with the findings of Bemstein, Stephan, and Davis (1979). When students in the failing group were asked to make open-ended statements regarding the cause for their failing grade on the test, $59.1 \%$ gave statements which referred to their ability and effort. Like students in the passing group, the highest used attribution was effort. Unlike the results for the passing students however, ability and task difficulty were tied as the second most frequently given attributions. This showed a lack of consistency between their high ratings of externality on the locus of causality dimension and their open-ended attribution statements. However, this is consistent with other studies which reported that failing students emphasize task difficulty as an important cause for their failure (Kovenkliouglu \& Greenhaus, 1978).

\section{Limitations of the Study}

Although the sample for this study was of interest to the researcher due to its academic vulnerability and its problematic success rate, it also posed some limitations as reflected in the findings. Students enrolled in this particular College Algebra course may have been predisposed not to think of themselves as successful students even when succeeding on an in-class test. Since success on the in-class test was the only operational definition for the passing group and students self-reported their test scores, the study did not take into consideration other factors that may have influenced the student's own definition of success. These may have included whether this was a first, second, or third 
attempt at this course. The dimensions of personal controllability and external controllability proved to be somewhat problematic to measure in this study. The findings pointed to a possible misunderstanding or confusion regarding the difference between these two dimensions (Russell \& Petrie, 1992; Winn, 1995).

The method used to distribute the questionnaire may have contributed another limitation to the study. Since the researcher was not available to go to every one of the 24 classes selected for this study, the instructions on how to complete the questionnaire may not have been expressed consistently among the sample. This may explain some of the inconsistencies between the ratings and the open-ended statements.

Another limitation to the study may have been the special challenges faced by students enrolled in a high-risk mathematics course such as College Algebra. Their attitude towards mathematics and this course in particular could have influenced the perception of performance. The fact that only College Algebra was selected for this study could have posed further limitations.

Finally, the operational and institutional definition used for passing and failing may not have represented student perceptions of success and failure. Any discrepancy in this definition could have affected the ratings within the attributions and the open-ended attribution statements.

\section{Conclusions}

The following conclusions are derived from the findings of this study. They provide responses to the research questions and address the support, or lack thereof, to the research hypotheses. 
1. For the locus of causality, stability, and personal controllability dimensions, the findings of this study support a significant difference between the attributions passing and failing students give for their performance on a College Algebra test.

2. Students in the passing group attributed their performance in the direction of internality (locus of causality dimension), stability (stability dimension), personal controllability (personal controllability dimension), and external controllability (external controllability dimension).

3. Students in the failing group attributed their performance in the direction of externality (locus of causality dimension), instability (stability dimension), other than personal controllability (personal controllability dimension), and external controllability (external controllability dimension).

4. The findings of this study failed to support the hypothesized assumption that passing students attribute their performance on the test to causes which others cannot control.

5. A statistically significant difference was found in the types of attribution statements made by students in the passing and failing groups in the categories of effort and task difficulty.

6. The open-ended statements given by students in the passing group reflected that effort and ability were the most frequently used attributions for their performance.

7. The open-ended statements given by students in the failing group reflected that effort, ability and task difficulty were the most frequently used attributions for their performance. 


\section{Implications for Practice}

The findings and conclusions of this study have the following implications for practice:

1. Since success in College Algebra has been known to have tremendous impact on program and degree completion, measuring the perception students have of their success or failure in College Algebra could be used to support the development of additional strategies for success. The CDSII along with other attitudinal surveys could prove to be valuable tools to educators seeking additional insight regarding student learning and how students explain their academic performance. This information could serve to explain how students explain their academic achievement or failure.

2. Students enrolled in high-risk courses such as College Algebra at a community college may not have the academic self-confidence to think of themselves as successful even when they are passing the course. Therefore, assessing for attributions and attributional style could provide valuable information to students in high-risk courses. The information derived from such assessment could be used within the counseling strategies available to students enrolled in high-risk courses. Counseling students in terms of their attributional style could prove beneficial and could further reduce the high failure rate in courses such as College Algebra.

\section{Recommendations for Future Research}

Based upon the results of this study, the following recommendations for future research are proposed:

1. One of the limitations of this study was that students identified as successful by a passing grade on a test may not have perceived themselves as successful 
mathematics students for a variety of reasons. This study, if replicated, could incorporate the academic history of students in previous mathematics courses as a source of additional information that could be used in the operational definition of successful students.

2. Further research could be conducted in settings where the personal controllability and external controllability dimensions can be more distinguishable from each other. Although the two aspects of control are conceptually distinct, they are easily collapsible by the respondents, as suggested by the findings of this study, and should be presented in a different manner.

3. A study incorporating student attributions for success or failure could be conducted comparing students in mathematics and another discipline. A study of that nature could determine a difference between student perceptions of what causes their academic success or failure in context of the subject matter.

4. Attribution retraining models as suggested by the literature (Dych, 1976; Fosterling, 1985; Heller \& Ziegler, 2000; Wilson, Damiani, \& Shelton, 2002) can be incorporated into intervention strategies within high-risk coursework. This intervention strategy should be explored for students reporting the causes for their success as external, unstable, and out of their control. These students who may have the ability and great potential for success are, at the same time, most at risk and should be trained to redirect their processing of attributions.

5. Studies may be conducted that incorporate whether enrollment in the mathematics class is a first, second, or third attempt as an additional variable for analysis. 
6. Further research may be conducted to determine if there is a relationship between students' age, ethnicity, or native language and their attributions for success or failure in a mathematics course.

7. Other studies examining the relationship between attributions and academic performance could be conducted based on a number of examinations within a course to assess any change in attributions.

8. In order to provide greater generalizability, similar studies could be conducted at other institutions using different populations. 


\section{REFERENCES}

Abramson, L. Y., Garber, J., \& Seligman, M. E. P. (1980). Learned helplessness in humans: An attributional analysis. In J. Garber \& M. E. P. Seligman (Eds.), Human helplessness: Theory and applications (pp. 3-34). New York: Academic Press.

American Federation of Teachers. (2003). Student persistence in college: More than counting caps and gowns. Retrieved February 10, 2004, from American Federation of Teachers Web site:

http://www.aft.org/higher_ed/downloadable/student_persistence.pdf

Amit, M. (1988). Career choice, gender and attribution patterns of success and failure in Mathematics. In A. Borbas (Ed.), Proceedings of the Annual Conference of the International Group for the Psychology of Mathematics Education: Vol. 1 (pp. 125-130). Veszprem, Hungary. (ERIC Document Reproduction Service No. ED411128)

Bandura, A. (1977). Social learning theory. Englewood Cliffs, NJ: Prentice Hall.

Bandura, A. (1982). Self-efficacy mechanism in human agency. American Psychologist, $37,122-147$.

Bandura, A. (1986). Social foundation of thought and action: A social-cognitive view. Englewood Cliffs, NJ: Prentice Hall.

Barrett, L. C. \& Peterson, C. (1987). Explanatory style and academic performance among university freshman. Journal of Personality and Social Psychology, 53, 603-607.

Bar-Tal, D. (1978). Attributional analysis of achievement related behavior. Review of Educational Research, 48, 259-271.

Bashford, J. (2002). Information capsule: Mathematics course progression. Retrieved January 9, 2004, from Miami Dade College, Institutional Research Web site: http://www.mdc.edu/ir/iracrobat/IC2002-11C.pdf

Bassarear, T. (1986). Attitudes and beliefs about learning, about mathematics, and about self which most seriously undermine performance in mathematics courses (Report No. SE049672). Paper presented at the Annual Conference of the New England Educational Research Organization, Rockport, ME. (ERIC Document Reproduction Service No. ED299147) 
Bernstein, W. M., Stephan, W. G., \& Davis, M. H. (1979). Explaining attributions for achievement: A path analytic approach. Journal of Personality and Social Psychology, 37, 1810-1821.

Biggs, J. B. (1987). Student approaches to learning and studying. Paper presented at the Australian Council for Educational Research, Melbourne, Australia.

Campbell, C. R., \& Henry, J. W. (1999). Gender differences in self-attributions: Relationship of gender to attributional consistency, style, and expectations for performance in a college course. Sex Roles, 41, 95-104.

Cantrell, S. W. (2001). Self-efficacy, causal attribution, self-esteem, and academic performance in baccalaureate nursing students (Doctoral dissertation, Georgia State University, 2001). Dissertation Abstracts International, 62(01), 140B. (UMI No. 3000897)

Council for Education Policy, Research, and Improvement (2002). Postsecondary progression of 1993-94 Florida public high school graduates: 2002 update. Tallahassee, FL: Author.

Covington, M. V. (1992). Making the grade a self-worth perspective on motivation and school reform. New York: Cambridge University Press.

Covington, M. V., \& Omelich, C. L. (1979). Are causal attributions causal? A path analysis of the cognitive model of achievement motivation. Journal of Personality and Social Psychology, 37, 1487-1504.

Cronbach, L. J., (1951). Coefficient alpha and the internal structure of tests. Psychometrika, 16, 296-334.

Diener, C. I., \& Dweck, C. S. (1978). An analysis of learned helplessness: Continuous changes in performance, strategy, and achievement cognitions following failure. Journal of Personality and Social Psychology, 36, 451-462.

Dweck, C. S. (1975). The role of expectations and attributions in the alleviation of learned helplessness. Journal of Personality and Social Psychology, 31, 674-685.

Dweck, C. S. (1999). Self theories: Their role in motivation, personality, and development. Philadelphia: Psychology Press.

Dossey, J. A., Mullis, I. V. S., Lindquist, M. M., \& Chambers, D. L. (1988). The mathematics report card: Are we measuring up? Trends and achievements based on the 1986 national assessment (Report No. 17-M-01). Princeton, NJ: National Assessment of Educational Progress, Educational Testing Service. (ERIC Document Reproduction Service No. ED300206) 
Fennema, E. (1976). Influences of selected cognitive, affective, and educational variables on sex-related differences in mathematics learning and study. In NIE Papers in Education and Work: No. 18 Women and Mathematics: Research Perspectives for Change, 79-135. Washington DC: National Institute of Education.

Findley, M. J., \& Cooper, H. M. (1983). Locus of control and academic achievement: A literature review. Journal of Personality and Social Psychology, 44, 419-427.

Forsyth, D. R. (1986). An attributional analysis of students' reactions to success and failure. In R. S. Feldman (Ed.), The social psychology of education: Current research and theory. New York: Cambridge University Press.

Forsyth, D. R., \& McMillan, J. H. (1991). Some practical proposals for motivating students. In R. J. Menges \& M. Svinicki (Eds.), Approaching instructional problems through theoretical perspectives: New directions for teaching and learning (pp. 53-66). San Francisco: Jossey-Bass.

Fosterling, F. (1985). Attributional retraining: A review. Psychology Bulletin, 98, 495-512.

Gilroy, M. (2002). Waking up students' math/science attitudes and achievement. The Hispanic Outlook on Higher Education, 13, 21-23.

Gist, M. E., Schwoerer, V., \& Rosen, B. (1989). Effects of alternative training methods on self-efficacy and performance in computer software training. Journal of Applied Psychology, 74, 884-891.

Heider, F. (1958). The psychology of interpersonal relations. New York: Wiley.

Heller, K. A., \& Ziegler, A. (2000). Effects of attribution retraining with female students gifted in physics. Journal for the Education of the Gifted, 23, 217-243.

Henry, J. W., Martinko, M. J., \& Pierce, M. A. (1993). Attributional style as a predictor of success in a first computer science course. Computers in Human Behavior, 9, 341-352.

Hill, T., Smith, N. D., \& Mann, M. F. (1987). Role of efficacy expectations in predicting the decision to use advanced technologies: The case of computers. Journal of Applied Psychology, 72, 302-313.

Hilton, J. L., Fein, S., \& Miller, D. T. (1993). Suspicion and dispositional inference. Personality and Social Psychology Bulletin, 19, 501-512. 
House, J. D. (2001). Cognitive-motivational predictors of science achievement of undergraduate students in health sciences majors. International Journal of Instructional Media, 28, 181-190.

House, J. D. (2003). Self-beliefs and science and mathematics achievement of adolescent students in Hong Kong: Findings from the Third International Mathematics and Science Study (TIMSS). International Journal of Instructional Media, 30, 195-212.

Jagacinski, C. M., \& Nicholls, J. G. (1990). Reducing effort to protect perceived ability: "They'd do it but I wouldn't." Journal of Educational Psychology, 82, 15-21.

Jones, E. E. (1990). Interpersonal perception. New York: Freeman.

Kivilu, J. M., \& Rogers, W. T. (1998). A multi-level analysis of cultural experience and gender influences on causal attributions to perceived performance in mathematics. British Journal of Educational Psychology, 68, 25-37.

Kloosterman, P. (1984, January). Attribution theory and mathematics education. Paper presented at the American Educational Research Association. (ERIC Reproduction Service No. ED244830)

Kloosterman, P. (1988). Self-confidence and motivation in mathematics. Journal of Educational Psychology, 80, 345-351.

Kloosterman, P. (1993, April). Students' views of knowing and learning mathematics: Implications for motivation. Paper presented at the annual meeting of the American Educational Research Association, Atlanta, GA.

Kloosterman, P., \& Gorman, J. (1990). Building motivation in the elementary mathematics classroom. School Science and Mathematics, 90, 375-382.

Kovenkliouglu, G., \& Greenhaus, J. H. (1978). Causal attributions, expectations, and task performance. Journal of Applied Psychology, 63, 698-705.

Kukla, A. (1972). Attributional determinants of achievement related behaviour. Journal of Personality and Social Psychology, 21, 166-174.

Kulas, H. (1996). Locus of control in adolescence: A longitudinal study. Adolescence, $31,2-81$.

Locke, E. A., \& Latham, G. P. (1990). A theory of goal setting and task performance. NJ: Prentice Hall. 
Miami Dade College. (2002). Fact book. Retrieved January 10, 2003, from Miami Dade College, Institutional Research Web site: http://www.mdc.edu/ir/undprp.pdf

Miami Dade College. (2003). Annual credit enrollment profile: Collegewide. Retrieved March 1, 2004, from Miami Dade College, Institutional Research Web site: http://www.mdc.edu/ir/datapages/Annual\%20CW\%20Credit.pdf

Miami Dade College. (2004). Fact book. Retrieved March 2, 2004, from Miami Dade College, Institutional Research Web site: http://www.mdc.eduir/Fact\%20Book/undprp.pdf

McAuley, E., Duncan, T. E., \& Russell, D. W. (1992). Measuring causal attributions: The Revised Causal Dimension Scale (CDSII). Personality and Social Psychology Bulletin, 18, 566-573.

McMillan, J. H., \& Forsyth, D. R. (1981). The impact of social psychological factors on school learning: An overview. Representative Research in Social Psychology, 12, 20-31.

McMillan, J. H., \& Forsyth, D. R. (1991). What theories of motivation say about why learners learn. New Directions for Teaching and Learning, 45, 39-52.

Meyer, M. R., \& Fennema, E. (1985). Predicting mathematics achievement for females and males from causal attributions. In S. K. Damarin \& M. Shelton (Eds.), Proceedings of the seventh annual meeting of the North American Chapter of the International Group for the Psychology of Mathematics Education (pp. 201-206). Columbus, $\mathrm{OH}$ : Authors.

Middleton, J. A., \& Spanias, P. A. (1999). Motivation for achievement in mathematics: Findings, generalizations, and criticisms of the research. Journal for Research in Mathematics Education, 30, 65-88.

Mitchell, T. R., Hopper, H., Daniels, D., George-Falvy, J., \& James, L. R. (1994). Predicting self-efficacy and performance during skill acquisition. Journal of Applied Psychology, 79, 506-517.

Morris, C. (2001). Research note: High risk courses. Retrieved May 10, 2003, from Miami Dade College, Institutional Research Web site: http://www.mdc.edu/mdc/ir/iracrobat/RNMar2_01.pdf

Morris, C. (2002a). Information Capsule: High risk courses. Retrieved October 30, 2003 from Miami Dade College, Institutional Research Web site: http://www.mdc.edu/mdc/ir/iracrobat/IC2002-14C.pdf 
Morris, C. (2002b). Information Capsule: Basic skills of the top 20\% of high school grads. Retrieved February, 10, 2003, from Miami Dade College, Institutional Research Web site: http://www.mdc.edu/mdc/ir/iracrobat/IC2002-18C.pdf

National Council of Teachers of Mathematics. (1989). Curriculum and evaluation standards for school mathematics. Reston, VA: Author.

Nicholls, J. G. (1984). Achievement motivation: Conceptions of ability, subjective experience, task choice, and performance. Psychology Review, 91, 328-346.

Nowicki, S., \& Strickland, B. R. (1973). A locus of control scale for children. Journal of Consulting Psychology, 40, 148-154.

Nunnally, J. C. (1978). Psychometric theory (2nd ed.) New York: McGraw-Hill.

Perry, R. P., \& Magnusson, J. L. (1989). Causal attributions and perceived performance: Consequences for college students' achievement and perceived control in different instructional conditions. Journal of Educational Psychology, 81, $164-172$.

Peterson, C. \& Seligman, M. E. P. (1984). Causal explanations as a risk factor for depression: Theory and evidence. Psychological Review, 91, 347-374.

Platt, C. W. (1988). Effects of causal attributions on first-term college performance: A covariance structure model. Journal of Educational Psychology, 80, 569-578.

Relich, J. (1984). Learned helplessness in arithmetic: An attributional approach to increased self-efficacy and division skills. In B. Southwell, R. Eyland, M. Cooper, J. Conroy, \& K. Collins (Eds.), Proceedings of the eighth annual international conference for the Psychology of Mathematics Education (pp. 487-503). Sydney, Australia: Authors. (ERIC Document Reproduction Service No. ED306127)

Relich, J., Debus, R. L., \& Walker, R. (1986). The mediating role of attribution and selfefficacy variables for treatment effects on achievement outcomes. Contemporary Educational Psychology, 11, 195-216.

Rotter, J. B. (1971, June). External control and internal control. Psychology Today, 5(1), $37-59$.

Rotter, J. B. (1982). The development and application of social learning theory: Selected papers. New York: Praeger.

Rotter, J. B. (1990). Internal versus external control of reinforcement: A case history of a variable. American Psychologist, 45, 489-493. 
Roueche, J. E., \& Baker, G. A. (1987). Access and Excellence: The open-door college. Washington, DC: Community College Press, American Association of Community and Junior Colleges.

Russell, D. (1982). The Causal Dimension Scale: A measure of how individual perceive causes. Journal of Personality and Social Psychology, 42, 1137-1145.

Russell, D., McAuley, E., \& Tarico, V. (1987). Measuring causal attributions for success and failure: A comparison of methodologies for assessing causal dimensions. Journal of Personality and Social Psychology, 52, 1248-1257.

Russell, R. K., \& Petrie, R. A. (1992). Academic adjustment of college students: Assessment and counseling. In S. D. Brown \& W. Lent (Eds.), Handbook of counseling psychology (2nd ed., pp. 485-511). New York: Wiley.

Skinner, E. A. (1996). A guide to constructs of control. Journal of Personality and Social Psychology, 71, 549-570.

Singham, M. (2003). The achievement gap: Myths and reality. Phi Delta Kappan, April, 586-591.

Solberg, V. S., O'Brien, K., Villareal, P., Kennel, R., \& Davis, B. (1993). Self-efficacy and Hispanic college students: Validation of the College Self-Efficacy Inventory. Hispanic Journal of Behavioral Sciences, 15, 80-95.

Strickland, B. R. (1989). Internal-external control experiences: From contingency to creativity. American Psychologist, 44, 1-12.

Taylor, M. S., Locke, E. A., Lee, L., \& Gist, M. (1984). Type A behavior and faculty research productivity: What are the mechanisms? Organizational Behavior and Human Performance, 34, 402-418.

Tollefson, N. (2000). Classroom expectations of cognitive theories. Educational Psychology Review, 12, 63-83.

University of Texas, Austin, Statistical Services (1995, June). Factor analysis using SAS PROC FACTOR. Retrieved June 23, 2004, from: http://www.utexas.edu/cc/docs/stat53.html

Weiner, B. (1972). Attribution theory, achievement motivation and the educational process. Review of Educational Research, 42, 203-215.

Weiner, B. (1974). Cognitive views of human motivation. New York: Academic Press. 
Weiner, B. (1979). A theory of motivation for some classroom experiences. Journal of Educational Psychology, 71, 3-25.

Weiner, B. (1982). The emotional consequences of causal ascriptions. In M.S. Clark \& S. T. Fiske (Eds.), Affect and cognition: The $17^{\text {th }}$ Annual Carnegie Symposium on Cognition (pp.185-200). Hillsdale, NJ: Erlbaum.

Weiner, B. (1984). Principles of a theory of student motivation and their application within an attributional framework. In R.E. Ames \& C. Ames (Eds.), Motivation in education: Volume 1. Student motivation. Orlando, FL: Academic Press.

Weiner, B. (1985). An attributional theory of achievement motivation and emotion. Psychological Review, 92, 548-573.

Weiner, B. (1986). An attributional theory of motivation and emotion. New York: Springer-Verlag.

Weiner, B. (1990). History of motivational research in education. Joumal of Educational Psychology, 82, 616-623.

Weiner, B., \& Kukla, A. (1970). An attributional analysis of achievement motivation. Journal of Personality and Social Psychology, 15, 1-20.

Wilson, T. D., Damiani, M., \& Shelton, N. (2002). Improving the academic performance of college students with brief attributional interventions. In J. Aronson (Ed.), Improving academic achievement: Impact of psychological factors on education (pp. 89-108). New York: Academic Press.

Wilson, T. D., \& Linville, P. W. (1982). Improving the academic performance of college freshmen: Attribution theory revisited. Journal of Personality and Social Psychology, 42, 367-376.

Wilson, T. D., \& Linville, P. W. (1985). Improving the performance of college freshmen with attributional techniques. Journal of Personality and Social Psychology, 49, 287-293.

Winn, T. D. (1995). Attributional differences between successful and unsuccessful college students on academic probation (Doctoral dissertation, Oklahoma State University, 1996). Dissertation Abstracts International, 57(02), 582A. (UMI No. 9618443)

Wolleat, P. L., Pedro, J. D., Becker, A. D., \& Fennema, A. (1980). Sex differences in high school students' causal attributions of performance in mathematics. Journal of Research in Mathematics Education, 11, 356-367. 
Wood, R. E., \& Locke, E. A. (1987). The relation of self-efficacy and grade goals to academic performance. Educational and Psychological Measurement, 47, 1013-1024. 
APPENDICES 
Appendix A - Cover Letter to Survey Instrument 


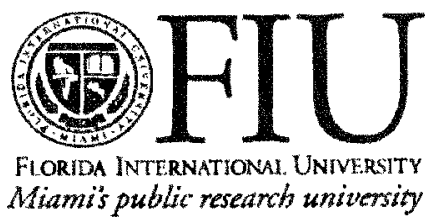

IRD Approyed

Date: $-12 / 05 / 03$

No: $-620203-00$

\section{Causal Attributions for Success or Failure by Passing and Failing Students in College Algebra}

You are being asked to participate in a research study. You will be completing the attached questionnaire which is designed to measure your attributional style. Attributional style is the way you explain good and bad events in your life. Your responses to the survey will be compared with your test grade on the College Algebra test just took in this class. There are no risks to you as a participant of this study. Although there may be no direct benefits to you as an individual, the study may identify new ways to look at achievement in mathematics.

The researcher will maintain the highest level of confidentiality. The information gathered for this study will be used only for the purposes of this study. The research results will be presented in a group format. Individuals will not be identified. Participation in this study will have no effect on your grades.

Completing the questionnaire will take approximately 15 minutes. The cover sheet and questionnaire will be collected as soon as you are finished.

Please feel free to contact me at (305) 237-7401, Miami Dade College, Wolfson Campus, Room 5501-6, or Dr. Janice Sandiford at (305) 348-3996, Florida International University, College of Education, University Park, Room ZEB 366. If you have any questions regarding being a human subject, you may contact Dr. Bernard Gerstman, the Chairperson of Florida International University's Institutional Review Board at (305) 348-3115 or (305) 348-2964.

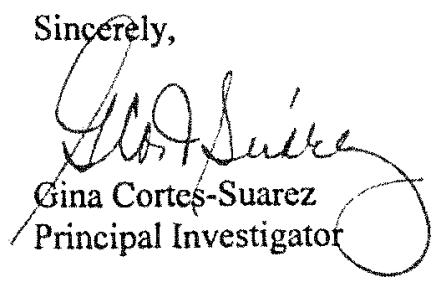


Appendix B - Causal Dimension Scale II (CDSII) 
1. How did you do on the test? Use a scale between 0 and 100. (0 means you had no right answers, 100 means all of your answers were right)

2. Why do you think you got that grade?

\section{CAUSAL DIMENSION SCALE (CDSII)}

Instructions: Think about the reason or reasons you have written above. The terms below concern your impressions or opinions of this cause or causes of your performance. Circle one number for each of the following questions.

Is the cause(s) something:

1. That reflects an aspect of yourself

2. Manageable by you

3. Permanent

4. You can regulate

5. Over which others have control

6. Inside of you

7. Stable over time

8. Under the power of other people

9. Something about you

10. Over which you have power

11. Unchangeable

12. Other people can regulate
$987654321 \quad$ reflects an aspect of the situation

$987654321 \quad$ not manageable by you

987654321 temporary

$987654321 \quad$ you cannot regulate

$987654321 \quad$ over which others have no control

$98776543321 \quad$ outside of you

$987654321 \quad$ variable over time

$987654321 \quad$ not under the power of other people

$987654321 \quad$ something about others

$987654321 \quad$ over which you have no power

$987654321 \quad$ changeable

$987654321 \quad$ other people cannot regulate

Mc Auley, E., Duncan, T. E. \& Russell, D. W. (1992). Measuring causal attributions: The Revised Causal Dimension Scale (CDSII). Personality and Social Psychology Bulletin, 18, 566-573. 
VITA

\section{GEORGINA CORTES-SUAREZ}

1973

Bachelor of Science in Education

University of Miami

Miami, Florida

1973-1978

Teacher

Miami-Dade County Public Schools

Miami, Florida

1978

Graduate Assistant

Miami Desegregation Center

University of Miami

Miami, Florida

1978

Master of Science in Education/Linguistics

University of Miami

Miami, Florida

1979-1980

Associate Director, Title VII Teacher Training Grant Miami-Dade Community College, North Campus Miami, Florida

$1980-1981$

Director, Title VII Teacher Training Grant

Miami-Dade Community College, North Campus

Miami, Florida

$1981-1982$

Associate Registrar

Miami-Dade Community College, North Campus

Miami, Florida

1983-1985

Executive Director, Hialeah Center

Miami-Dade Community College, North Campus

Miami, Florida

1985-1989

Faculty and Department Chairperson Basic Communication Studies Department Miami-Dade Community College, North Campus Miami, Florida 
Associate Dean

Division of Communications

Miami-Dade Community College, North Campus

Miami, Florida

$1996-2000$

Dean of Academic Affairs

Miami-Dade Community College, Kendall Campus

Miami, Florida

2000-2003

Dean of Academic Affairs

Miami-Dade Community College, North Campus

Miami, Florida

2003-Present

Associate Provost for College Accreditation

Miami Dade College

Miami, Florida 